\title{
Article \\ Optimized Planning of Distribution Grids Considering Grid Expansion, Battery Systems and Dynamic Curtailment
}

\author{
Ouafa Laribi * and Krzysztof Rudion
}

check for updates

Citation: Laribi, O.; Rudion, K. Optimized Planning of Distribution Grids Considering Grid Expansion, Battery Systems and Dynamic Curtailment. Energies 2021, 14, 5242. https://doi.org/10.3390/en14175242

Academic Editors: Pavlos S. Georgilakis and Habib M. Kammoun

Received: 30 June 2021

Accepted: 16 August 2021

Published: 24 August 2021

Publisher's Note: MDPI stays neutral with regard to jurisdictional claims in published maps and institutional affiliations.

Copyright: (c) 2021 by the authors. Licensee MDPI, Basel, Switzerland. This article is an open access article distributed under the terms and conditions of the Creative Commons Attribution (CC BY) license (https:/ / creativecommons.org/licenses/by/ $4.0 /)$.
Institute of Power Transmission and High Voltage Technology, University of Stuttgart, 70174 Stuttgart, Germany; rudion@ieh.uni-stuttgart.de

* Correspondence: ouafa.laribi@ieh.uni-stuttgart.de
Keywords: grid planning; grid reinforcement; grid expansion; cost-optimal planning; battery; storage; power curtailment; distribution systems; load flow calculation; mixed integer linear programming

\section{Introduction}

Traditionally, the applied grid planning for distribution systems in Germany is most commonly based on a deterministic approach, which considers typically two worst case scenarios for the load and feed-in [1,2]. The considered scenarios are the heavy load flow scenario depicting maximum load and no generation, and the reverse power flow scenario replicating minimal load and maximum generation [3]. Yet, this approach disregards the probability of the considered worst case scenarios as well as the variability of the connected load and generation. This could lead to an overdimensioning of the planned grid $[4,5]$. Furthermore, the traditional planning methods applied by grid operators lack process automation and standardized financial models, and they also disregard the application of innovative planning instruments such as BSS and DPC [6].

Many contributions deal with the use of BSS for grid-supporting applications as the prevention of grid congestion [7]. For instance, in [8-10], BSS are applied for voltage stability purposes. In [11,12], they are used to prevent line overloads. The contribution of BSS to fulfill the $(n-1)$ security criterion in high-voltage grids has been treated for instance in [13]. In [14-16], the BSS application to fulfill the $(n-1)$ criterion in the grid planning has been combined with the use of DPC.

Few contributions suggest the use of BSS and power curtailment in combination with the traditional grid expansion in the grid planning. In [17], a multi-stage expansion of distribution grids in due consideration of storage deployment is proposed using a genetic algorithm (GA) to minimize the costs of the grid expansion. However, the investment costs of the storages have not been considered in the cost calculation, since they have not been assumed as DSO property but rather lent from a storage owner for grid services against an 
annual fee. In such case, the DSO is reliant on existing storages, and cannot dimension and position the storages depending on the need and on the cost minimal solution.

In [18], a multi-stage grid expansion method in due consideration of centralized and decentralized storage systems is proposed for active distribution grids. A co-optimization has been here used to minimize the total investment and operating costs of the network. The method has been applied on $20 \mathrm{kV}$ grids for an extreme load daily scenario but not for high feed-in scenarios. Besides, the reactive power has not been considered in the planning. This can lead to errors in the nodal voltage and power flow calculation, and hence to deviate planning results.

The planning method proposed in this paper has been implemented in a time seriesbased environment in order to consider the variation of the load and generation in the planning process. Compared to the works stated above, the proposed approach combines the traditional grid expansion with the application of BSS and DPC within a planning algorithm for an automated reinforcement of distribution grids. Based on these possible grid reinforcement instruments, the algorithm determines the least-cost combination of reinforcement measures that prevent the forecasted overloads and voltage limit violations in the grid, over a simulation time of one year with $15 \mathrm{~min}$ time resolution.

Besides, the planning algorithm uses a linearized load flow calculation, in which both active and reactive power are considered to minimize the resulting errors, as compared to the normal Newton-Raphson load flow calculation.

Further, the planning of the grid is realized here in one step, in consideration of the total costs of the grid reinforcement measures. In order to determine a cost-optimized planning of the grid, a mixed integer linear programming optimization (MILP) has been implemented in the planning algorithm with the main goal of minimizing the total planning costs over a considered economic life of 40 years.

The delivered results from planning algorithm comprise the required line expansion measures including type and location of the expansion, the required capacity, rated power and scheduling of the BSS, as well as the scheduling of the DPC.

In the following, a description of the classical grid expansion method is given in Section 2. Section 3 gives an overview of the input data generation and the proposed new planning approach. Section 4 outlines the results of the classical planning method and of the proposed planning algorithm on a real middle-voltage (MV) grid for different planning variants. In Section 5, the results of both classical and innovative grid methods are presented and compared with each other, and the main findings are presented. Section 6 summarizes the objectives and the results of this work.

\section{Classical Planning of MV Grids}

In order to evaluate the added value of the proposed innovative planning approach, a classical planning method for HV and MV grids according to [1] has been implemented in this work as the reference method. This reference method has been described and assumed in [1] as the common used planning method by grid operators in Germany. In the following, a description of this classical grid planning approach is presented.

\subsection{Determination of the Load and Generation Scenarios}

Within the planning of the grid, different load and generation case scenarios have to be considered in order to ensure the reliability of the power supply. For that, system operators typically use two extreme load and generation scenarios for the dimensioning of the network. The first case scenario represents a high power demand of the loads at low feed-in power from the RES into the grid, and will be in this work termed HLLG (high load, low generation). The second case scenario illustrates a high feed-in power from RES into the grid at low power demand of the loads and will be in this work termed LLHG (low load, high generation). The power demand is hereby calculated based on the contracted power capacity of the load at the grid connection point and the specific simultaneity factor of the load. This simultaneity factor is usually determined by the system operators by means of 
realized measures of the supplied load. The feed-in power of RES is calculated based on the installed power and the simultaneity factor of renewable power generation plants. This factor is usually calculated by means of reference measures on renewable power plants in the region [1]. Table 1 shows the adopted simultaneity factors of the load and RES power generation for the deterministic grid planning, depending on the considered case scenario and the voltage level of the network, according to [1].

Table 1. Adopted simultaneity factors of the load and power generation in the grid planning [1].

\begin{tabular}{ccccc}
\hline \multirow{2}{*}{ Plant Type } & \multicolumn{2}{c}{ MV Grid } & \multicolumn{2}{c}{ LV Grid } \\
\cline { 2 - 5 } & HLLG & LLHG & HLLG & LLHG \\
\hline Load & $100 \%$ & $30 \%$ & $100 \%$ & $20 \%$ \\
Wind & $0 \%$ & $100 \%$ & - & - \\
PV & $0 \%$ & $85 \%$ & $0 \%$ & $85 \%$ \\
\hline
\end{tabular}

In the case of the high load and low generation scenario (HLLG), the load flow in the grid is calculated based on $100 \%$ of the connected load capacity and $0 \%$ of the renewable feed-in power. In the case of the low load and high generation scenario (LLHG), the load is reduced to $30 \%$ in the MV grid and to $20 \%$ in the LV grid as compared with the connected load capacity to the grid, respectively. However, the renewable feed-in power is assumed by $100 \%$ of the installed wind capacity, and $85 \%$ of the installed PV capacity.

\subsection{Relevant Grid Restrictions}

Based on the previously defined relevant load and generation scenarios, load flow calculations are realized to determine whether or not the voltage magnitude on the nodes and the power flow through the network equipment comply with the allowed voltage and power flow limits, respectively. As presented in Figure 1, the voltage magnitude in MV grids is limited to $-1.5 \%$ and $+5 \%$ of the nominal voltage $U_{N}$ [1].

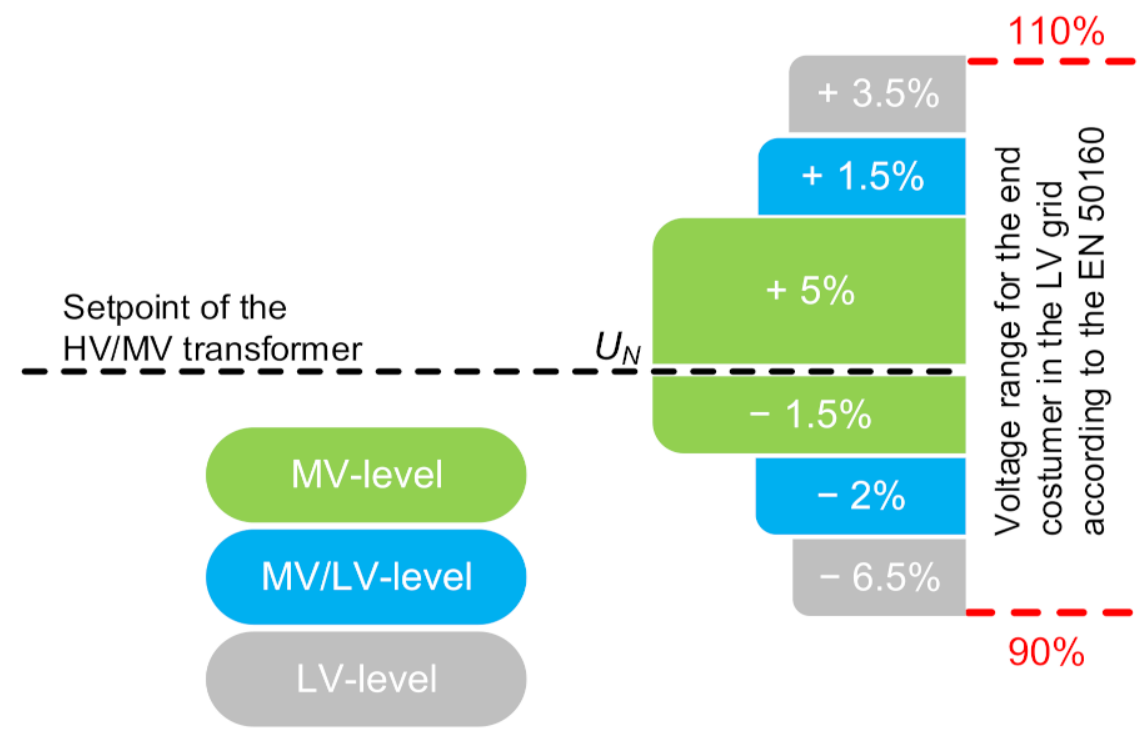

Figure 1. Allowed voltage ranges in the normal state depending on the voltage level [1].

The loading limits of the equipment are specified for MV grids as presented in Table 2. Hereby, the $(n-1)$ criterion is required only for the HLLG case scenario. Therefore, a 50\% limit of the current-carrying capacity of transformers and lines is defined in this case, to maintain a reserve capacity in the event of an outage. In the case of LLHG, the $(n-1)$ criterion is not required. Therefore, transformers and power lines can be operated at $100 \%$ of their current-carrying capacities [1]. 
Table 2. Relevant equipment loading limits for the deterministic planning of MV grids [1].

\begin{tabular}{ccc}
\hline & MV Grid \\
\hline & HLLG & LLHG \\
\hline Transformer & $50 \%$ & $100 \%$ \\
Power line & $50 \%$ & $100 \%$ \\
\hline
\end{tabular}

\subsection{Standard Grid Expansion Measures}

In case of violation of the previously described grid restrictions, the considered network is to be expanded. The applied expansion measures depend on the determined congestion. In the case of an overload of a network component such as transformer or power line, the component is to be reinforced by adding an identical component at maximum, or replaced by a standard network component. If adding one identical component to the existing one is sufficient to remedy the overload problem, then the existing grid component is to be reinforced by one identical component. Otherwise, the existing component is to be replaced by as many parallel standard components as necessary to prevent the overloads. Table 3 shows the power or the current-carrying capacity of the adopted standard equipment for the network planning [1].

Table 3. Standard equipment adopted for the planning of MV grids [1].

\begin{tabular}{cc}
\hline & Power or Current-Carrying Capacity \\
\hline Transformer & 40 MVA \\
Cable & $361 \mathrm{~A}$ \\
\hline
\end{tabular}

In case of voltage limit violations, the concerned feeder is to be split at two-thirds of the distance from the MV transformer busbar to the furthermost critical node into two feeders. The load flow through the old feeder can be hence reduced. If the split of the feeder is not sufficient to overcome the voltage violation, a further split can be realized, provided it is possible and appropriate. Otherwise, the split feeder is to be reinforced through parallel standard cables in order to reduce the line impedance and prevent the voltage limits transgression [1].

\subsection{Classical Planning Process of MV Grids}

Figure 2 illustrates the procedure steps by the planning of MV grids. In a first step, the additional installed power of load and RES in a municipality is allocated to the MV grids of the municipality. After that, the assigned additional installed power to the MV grid is portioned into power plants depending on the plant type and the rated power of one plant. The plants are then allocated randomly to the grid nodes with respect to further constraints as described in [1].

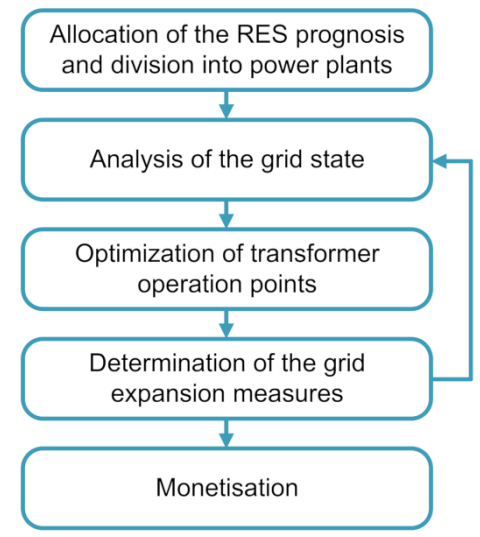

Figure 2. Classical planning method for medium-voltage grids. 
In a further step, the state of the grid is analyzed with the help of load flow calculations, based the adopted load and generation scenarios described in Section 2.1.

In the case of limit violations, the voltage setpoint of the HV/MV transformer is adjusted at first to ensure as few voltage transgressions as possible. The adjustment of the transformer operation point can also have a positive impact on the equipment loading. Then, the network state is to be analyzed again. In case of remaining limit violations, transformer overloads are treated at first by reinforcing or replacing the existing overloaded transformer. After remedy of the transformer congestion, voltage limit transgressions are treated next by means of feeder split or cable reinforcement as described in Section 2.3. After remedy of the transformer congestion and recalculation of the network state, the remaining line overloads are to be treated at last by reinforcing or replacing the overloaded lines. Once the network is expanded appropriately and no more congestion is determined, the total costs of the expansion measures are calculated. Figure 3 shows the iterative adopted proceeding for the determination of the required expansion measures.

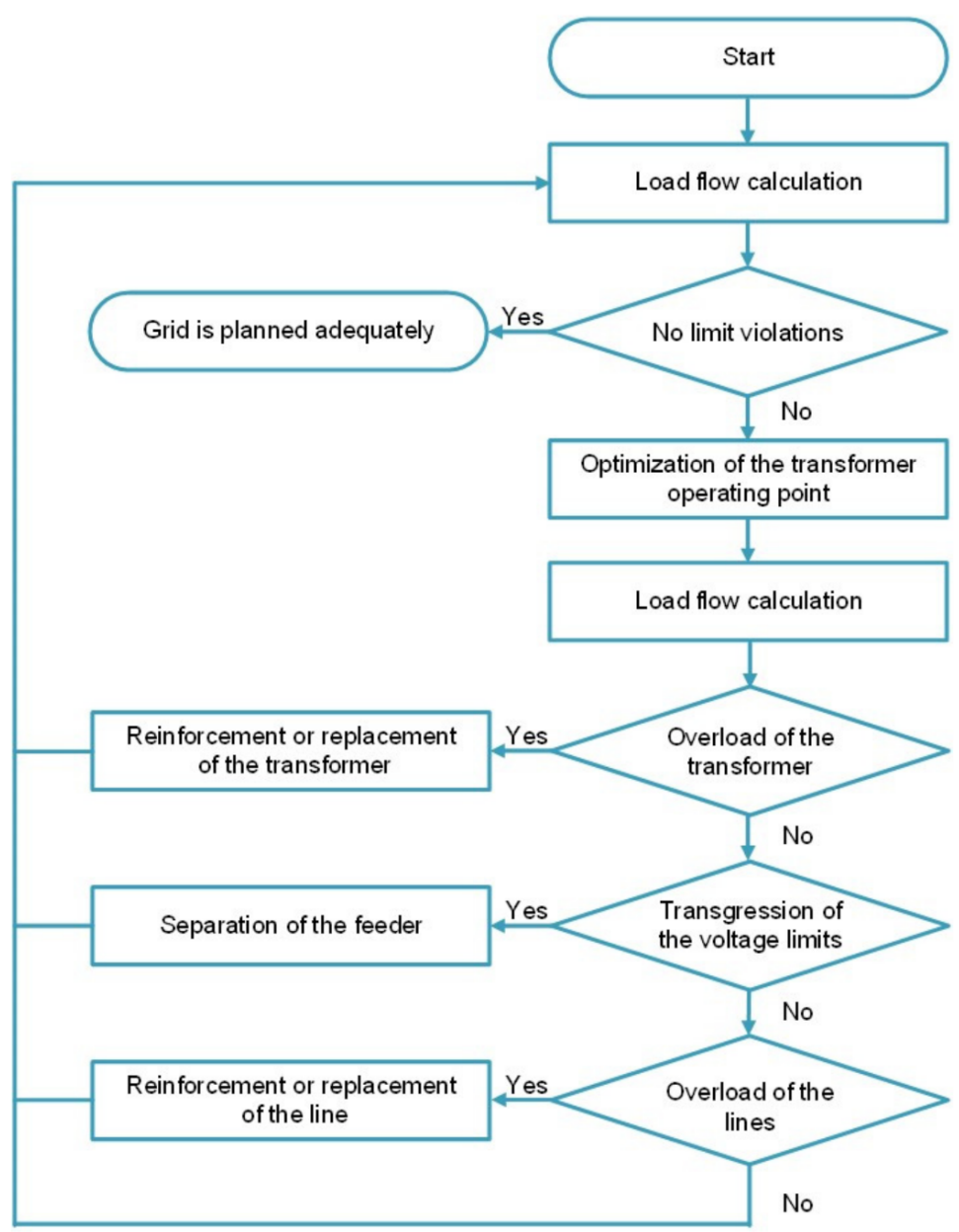

Figure 3. Proceeding for the selection of the required expansion measures within the classical planning method for medium-voltage grids.

\section{New Planning Method}

\subsection{Generation of the Input Data}

This section illustrates the adopted approach for the generation of the times series for load and RES. The generated time series are then used later in the planning algorithm, described in the subsequent section. Further, this section describes, in detail, the used method for the load flow calculation in the planning algorithm, based on a real modeled MV grid. 


\subsubsection{Modeling of a Medium-Voltage Grid}

A real $20 \mathrm{kV}$ grid in Germany was modeled to test the developed planning algorithm. Table 4 presents the specifications of the test system.

Table 4. Specifications of the test system.

$\begin{array}{cc}\text { Voltage Level } & 20 \mathrm{kV} \\ \text { Node number } & 132 \text { nodes } \\ \text { Power line number } & 131 \text { lines } \\ \text { Total length of the lines } & 71.4 \mathrm{~km}\end{array}$

Figure 4 shows a simplified demonstrative illustration of the considered MV grid (MV Grid 1), which has mainly an open ring structure. Due to the high number of grid nodes, only a part of the nodes and of the lines was depicted in the figure. The considered power system includes PV plants which are connected to 76 nodes of the grid, as well as wind plants which are connected to node 5. Line 6 connects here the wind power plants (node 5) to the main $20 \mathrm{kV}$ busbar (node 15).

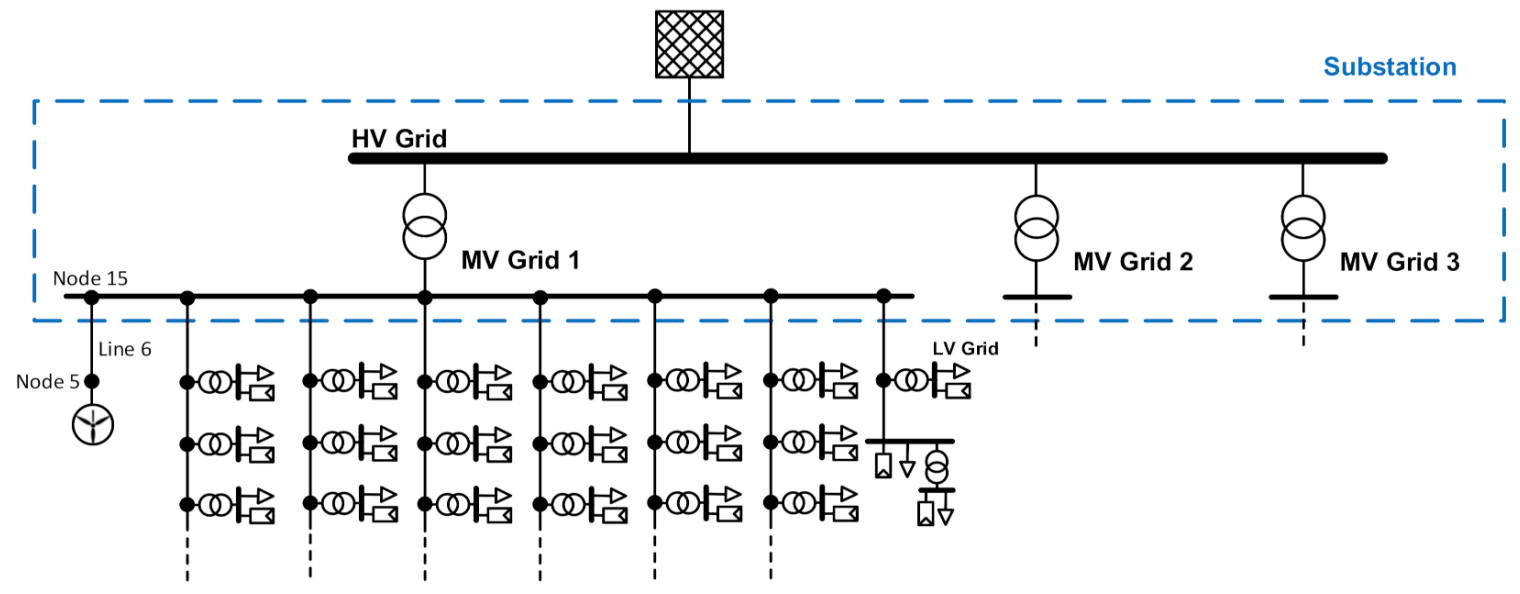

Figure 4. Simplified demonstrative illustration of the considered MV grid.

\subsubsection{Generation of Time Series for the Load and RES Power}

It is not common to carry out measurements at the MV level. Therefore, there are commonly no available time series for the injection power on the grid nodes. The time series of the connected load and RES power were generated in this research work for the considered MV grid (MV Grid 1) according to the scenario 2030 as follows:

1. In the first step, the time series of the connected RES in 2017 were calculated for every node depending on the installed power on every node and the normalized time series for reference PV, wind and biogas plants in the region.

2. In the second step, the time series of the total load in MV Grid 1 was calculated as the difference between the residual load of the HV/MV transformer and the accumulated times series of RES in 2017 (passive sign convention).

3. Then, the time series of the total load in MV Grid 1 were divided over the grid nodes proportionally to the share of every node in the total installed load of the grid. The installed load in the grid was then assumed as constant until 2030.

4. In a further step, the forecasted installed power of RES in the entire region including the MV grid by 2030 was calculated depending on scaling factors, provided from the responsible grid operator, and the installed power of RES in 2017.

5. The additional installed power of RES in the entire region was then calculated as the difference between the forecasted power by 2030 and the installed power of RES in the grid in 2017. 
6. After that, the additional installed power of RES in the entire region by 2030 was divided equally over the eight MV grids included in the region.

7. Finally, the additional installed power of RES in the considered MV grid by 2030 was added to the already installed RES power in the grid, and the time series of RES on every node by 2030 was calculated depending on the total installed RES by 2030, the share of every node in the total installed RES in 2017 and the reference time series for $\mathrm{PV}$, wind and biogas plants.

\subsubsection{Linearization of the Load Flow Calculation}

Since the planning algorithm, described in the subsequent section, uses linear optimizations, the linearization of the load flow is here necessary in order to model the required voltage and power flow limits in the form of linear constraints. The linearization of the voltage and current flow was realized in this paper premised on the proposed linearization in [19-21]. Within the normal Newton-Raphson load flow method, the correction of the node voltage magnitudes and voltage angles can be calculated iteratively in per-unit system with the help of the inverse of the Jacobian matrix [22]:

$$
\left(\begin{array}{c}
(\Delta \vartheta) \\
(\Delta u)
\end{array}\right)=\left(J^{-1}\right) \times\left(\begin{array}{c}
(\Delta p) \\
(\Delta q)
\end{array}\right)
$$

$(\Delta p)$ : Vector containing the real power mismatches, which represent the difference between the real active injection power and the calculated active injection power in $p u$.

$(\Delta q)$ : Vector containing the reactive power mismatches, which represent the difference between the real reactive injection power and the calculated reactive injection power in $p u$.

$(\Delta \vartheta)$ : Vector containing the corrections of the node voltage angles in Radian.

$(\Delta u)$ : Vector containing the corrections of the node voltage angles in $p u$.

$\left(J^{-1}\right)$ : The inverse of the Jacobian matrix.

Considering a power system with $n$ nodes, the voltage value and voltage angle of the slack node are assumed to be known $\left(\underline{u}_{\text {slack }}=1 e^{j 0} \mathrm{pu}\right)$. For the rest of the nodes, the better approximation of the voltage angles and magnitudes can be written for every node $i$ subject to the iteration count $v$ as follows:

$$
\begin{gathered}
\vartheta_{i}^{(v+1)}=\vartheta_{i}^{(v)}+(\Delta \vartheta)^{(v)}, \forall i \in\{1,2, \ldots, n-1\} \\
u^{(v+1)}=u^{(v)}+(\Delta u)^{(v)}, \forall i \in\{1,2, \ldots, n-1\}
\end{gathered}
$$

$\vartheta_{i}$ : Voltage angle on a node $i$ in radian.

$u_{i}$ : Voltage magnitude on a node $i$ in $p u$.

The Jacobian matrix and the error in injection power are to be readjusted at every iteration depending on the latest approximated voltage and angle values. The iterative process is to be carried on until the error in injection power reaches a predefined accuracy level $\varepsilon$.

$$
\Delta p<\varepsilon \text { and } \Delta q<\varepsilon
$$

The linearization of the node voltage calculation was realized as described hereafter. At first, the load flow was calculated for a selected operating point according to the NewtonRaphson method. After reaching the predefined accuracy of $\varepsilon=10^{-8}$ as in (4), the resulting better approximations of the voltage angles and magnitudes were determined according to (2) and (3). If the load flow calculation (LFC) converges for instance after 3 iterations, the resulting voltage angles and magnitudes can be written as:

$$
\left(\begin{array}{l}
(\vartheta) \\
(u)
\end{array}\right)^{(3)}=\left(\begin{array}{c}
(\Delta \vartheta) \\
(\Delta u)
\end{array}\right)^{(2)}+\left(\begin{array}{l}
(\vartheta) \\
(u)
\end{array}\right)^{(2)}=\left(J^{-1}\right)^{(2)} \times\left(\begin{array}{c}
(\Delta p)^{(2)} \\
(\Delta q)^{(2)}
\end{array}\right)+\left(\begin{array}{c}
(\vartheta) \\
(u)
\end{array}\right)^{(2)}
$$


The vector of the error in injection power can be rewritten depending on the vector of the set injection power and the vector of the calculated power as follows:

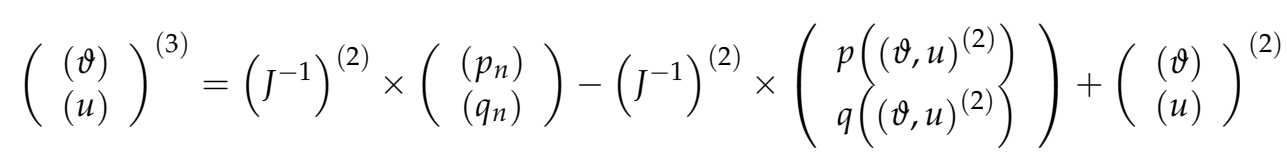

The adopted linearization of the node voltage calculation is based on a simplification, which assumes that the matrix $(A)$ and the vector $(C)$ of the system Equation (6) are constant:

$$
\begin{aligned}
& (A)=\left(J^{-1}\right)^{(2)} \\
& (C)=-\left(J^{-1}\right)^{(2)} \times\left(\begin{array}{c}
p\left((\vartheta, u)^{(2)}\right) \\
q\left((\vartheta, u)^{(2)}\right.
\end{array}\right)+\left(\begin{array}{c}
(\vartheta) \\
(u)
\end{array}\right)^{(2)}
\end{aligned}
$$

By doing this, the calculation of the voltage magnitudes and angles of the power system can be simplified according to the linear system Equation (9), where $\left(p_{n}\right)$ and $\left(q_{n}\right)$ are the vectors of the active and reactive injection power, respectively.

$$
\left(\begin{array}{c}
(\vartheta) \\
(u)
\end{array}\right)=(A) \times\left(\begin{array}{c}
\left(p_{n}\right) \\
\left(q_{n}\right)
\end{array}\right)+(C)
$$

Unlike the proposed linearization method in [19-21], where the Newton-Raphson load flow calculation is applied for just one iteration to build the linear system, the proposed linearization method in this work applies the Newton-Raphson load flow calculation until convergence. Then, the resulting inverse of the Jacobian matrix and the resulting vector of the calculated power and the vector of the calculated voltage values are then used in the linear system to reach a better approximation of the linearized LFC.

Considering a line of the power system connected between nodes $i$ and $j$, the complex current flow $\underline{i}_{i j}$ through the line can be calculated depending the complex node voltages and the line admittance in per-unit system as follows:

$$
\underline{i}_{i j}=\underline{y}_{i j} \times\left(\underline{u}_{i}-\underline{u}_{j}\right)
$$

$i_{i j}$ : Current flow through a line connected between node $i$ and $j$ in $p u$.

$\underline{y}_{i j}$ : Admittance of the line connected between node $i$ and $j$ in $p u$.

By rewriting the admittance $\underline{y}_{i j}$ depending on the conductance $g_{i j}$ and the susceptance $b_{i j}$ of the line, and by rewriting the complex node voltages in function of the voltage magnitude and voltage angles, the current flow in (10) can be expressed as follows:

$$
\underline{i}_{i j}=\left(g_{i j}+j b_{i j}\right) \times\left(u_{i} \times\left(\cos \left(\vartheta_{i}\right)+j \sin \left(\vartheta_{i}\right)\right)-u_{j} \times\left(\cos \left(\vartheta_{j}\right)+j \sin \left(\vartheta_{j}\right)\right)\right)
$$

$b_{i j}$ : Susceptance of the line connected between node $i$ and $j$ in $p u$.

$g_{i j}$ : Conductance of the line connected between node $i$ and $j$ in $p u$.

The linearization of the current flow was realized in this paper premised on the proposed linearization in [19].

Taking into consideration that the voltage angles in power systems are generally below $30^{\circ}$, the small-angle approximation as in (12) can be adopted.

$$
\begin{aligned}
& \cos \left(\vartheta_{i}\right) \approx 1 \\
& \sin \left(\vartheta_{i}\right) \approx \vartheta_{i}
\end{aligned}
$$


Besides, the voltage magnitudes on the nodes are assumed to be near $1 p u$ and must not exceed a maximum deviation of $5 \%$ in medium-voltage grids [1]. On these grounds, the following simplification was adopted:

$$
u_{i} \times \vartheta_{i} \approx \vartheta_{i}
$$

For the sake of simplicity, the complex current (11) was split in active current $i_{i j, p}$ and reactive current $i_{i j, q}$, which based on the simplifications (12) and (13), were expressed as follows:

$$
\begin{aligned}
& i_{i j, p}=g_{i j} \times\left(u_{i}-u_{j}\right)-b_{i j} \times\left(\vartheta_{i}-\vartheta_{j}\right) \\
& i_{i j, q}=b_{i j} \times\left(u_{i}-u_{j}\right)+g_{i j} \times\left(\vartheta_{i}-\vartheta_{j}\right)
\end{aligned}
$$

\subsubsection{Quality of the Linearized Load Flow Calculation}

The linearized LFC method was applied on the considered MV grid in order to evaluate its quality. The linearized calculation of the load flow was performed for one year with 15 min time resolution, according to the scenario 2030 for the installed load and RES. The resulting voltages and current flow values were then compared with the results of the standard Newton-Raphson load flow analysis. For that, the mean absolute error and the maximum absolute error were calculated taking into consideration all time steps of the year. For instance, the mean absolute error and the maximum absolute error of the approximated voltage magnitudes were calculated as follows:

$$
\begin{gathered}
A E_{\text {mean }}=\frac{\sum_{i=1}^{N_{\text {nodes }}} \sum_{t=1}^{N_{\text {steps }}}\left|U_{N R, i, t}-U_{\text {lin }, i, t}\right|}{N_{\text {nodes }} \times N_{\text {steps }, q}} \\
A E_{\text {max }}=\max \left\{\left|U_{N R, i, t}-U_{\text {lin }, i, t}\right|\right\} \\
\forall i \in N, \forall t \in T_{\text {year }, q}
\end{gathered}
$$

$U_{l i n, i, t}:$ Resulting voltage magnitude value from the linearized LFC for node $i$ at time step $t$ in $k V$.

$U_{N R, i, t}:$ Resulting voltage magnitude value from the Newton-Raphson LFC for node $i$ at time step $t$ in $k V$.

$N_{\text {nodes }}$ : Number of grid nodes.

$N_{\text {steps }}$ : Number of time steps over one year with a time resolution of a quarter-hour.

Table 5 shows the calculated mean absolute errors and maximum absolute errors for the voltage magnitude, voltage angle as well as for the real and imaginary part of the complex current. It can be deduced from the table, that the voltage values were better approximated than the current values. The maximum errors by the voltage calculation amount to $0.022 \mathrm{kV}$ for the voltage magnitude and $0.037^{\circ}$ for the voltage angle. By the current calculation, the maximum errors amount to $8.55 \mathrm{~A}$ for the real part and to $6.16 \mathrm{~A}$ for the imaginary part of the current. All in all, the errors due to the linearized LFC are relatively low and the approximation of the voltage and current values are acceptable.

Table 5. Comparison of the linearized LFC with the Newton-Raphson LFC.

\begin{tabular}{ccc}
\hline Results & Mean Absolute Error & Maximum Absolute Error \\
\hline Voltage magnitude $U_{i} / k V$ & 0.0002 & 0.022 \\
Voltage angle $\vartheta_{i} /{ }^{\circ}$ & 0.0004 & 0.037 \\
Real current $I_{p} / A$ & 0.022 & 8.55 \\
Imaginary current $I_{q} / A$ & 0.23 & 6.16 \\
\hline
\end{tabular}




\subsection{Planning Algorithm for MV Grids}

The developed planning algorithm is based on a MILP optimization which comprises linear objective functions and linear constraints. In this section, a detailed description of the implemented objectives and constraints is presented.

The implemented objective functions in the planning algorithm are optimized decreasingly from the most to the least prioritized objective depending on their priority order. The implemented objective with the highest priority order in the optimization aims to minimize the total costs of the grid expansion, BSS and DPC application over a considered economic life of 40 years:

$$
\min \left\{\operatorname{Cost}_{G E}+\operatorname{Cost}_{B S S}+\operatorname{Cost}_{D P C}\right\}
$$

Cost $_{G E}$ Costs of the grid expansion measures in EUR million (optimization variable). Cost $_{B S S}$ Costs of the BSS application in EUR million (optimization variable).

Cost $_{D P C}$ Costs of the DPC application in EUR million (optimization variable).

The cost calculation for the grid expansion $\operatorname{Cost}_{G E}$, the application of BSS Cost ${ }_{B S S}$ and for the application of DPC is described detail in Sections 3.2.1-3.2.3.

The objective Equation (18), minimizing of the total costs over the economic life, was implemented with the highest priority order in the optimization. This objective function enables also the exclusion of the nodes, which have little influence on preventing grid congestions, from the BSS placement. This results hence in an optimal placement of the BSS in the grid.

Further, the linear objective Equation (19) was implemented in the optimization as second objective function with less priority than (18). This function minimizes the stored energy in the BSS at every time step, enabling the discharge of the BSS when no grid congestion is prognosticated, and minimizing hence the number of performed battery cycles.

$$
\min \left\{\sum_{s=1}^{N_{\text {nodes }}} \sum_{t=1}^{N_{\text {steps }}} E_{s, t}\right\}
$$

$E_{s, t}:$ Storage energy of a BSS $s$ at time step $t$ in $M W h$ (optimization variable).

The storage energy at every time step was calculated as a function of the storage power of the BSS.

$$
E_{s, t}=P_{s, t} \times \Delta t_{\text {step }}+E_{s, t-1}
$$

$P_{s, t}:$ Storage power of the BSS $s$ at time step $t$ in $M W$ (optimization variable).

Note that during the optimization an efficiency coefficient equal to 1 was adopted by charging and discharging the BSS as in (20), in order to avoid an excessive use of the storage losses when preventing the grid overloads. After completion of the optimization, the values of the storage energy were corrected according to a predefined efficiency coefficient below 1 . This efficiency coefficient was yet considered for the calculation of the BSS costs within the optimization, since an efficiency coefficient below 1 leads to less required storage capacity.

Besides the objective functions, linear constraints were implemented in the optimization to fulfill the required grid restrictions in MV grids. The application of grid expansion, BSS and DPC was, thereby, considered. When using the DPC, both active and reactive power are curtailed. The curtailed reactive power was considered depending on the curtailed active power and the phase change angle of the power plant:

$$
\begin{gathered}
\Delta Q_{P V, i, t}=\Delta P_{P V, i, t} \times \tan \varphi_{P V, i} \\
\Delta Q_{\text {Wind }, i, t}=\Delta P_{\text {Wind }, i, t} \times \tan \varphi_{\text {Wind }, i} \\
\forall i \in N, t \in T_{\text {year }, q}
\end{gathered}
$$

$\Delta Q_{P V, i, t}:$ Curtailed PV reactive power on node $i$ at time step $t$ in Mvar (optimization variable).

$\Delta Q_{\text {Wind }, i, t}:$ Curtailed wind reactive power on node $i$ at time step $t$ in Mvar (optimization variable). 
$\varphi_{i}$ : Phase change angle of the power plant connected to node $i$.

The contribution of the BSS and DPC in maintaining the voltage within the permitted range was implemented based on the linear system Equation (9):

$$
0.985 p u \leq(A) \times\left(\begin{array}{c}
\left(p_{n, t}\right)+\left(p_{s, t}\right)+\left(\Delta p_{P V, t}\right)+\left(\Delta p_{\text {Wind }, t}\right) \\
\left(q_{n, t}\right)-\left(\Delta q_{P V, t}\right)-\left(\Delta q_{\text {Wind }, t}\right)
\end{array}\right)+(C) \leq 1.05 p u
$$

$\left(p_{n, t}\right)$ : Vector of the original residual power injection of the grid nodes at time step $t$ in $p u$.

$\left(p_{s, t}\right)$ : Vector of the storage power of the grid nodes at time step $t$ in $p u$ (optimization variables).

$\left(\Delta p_{P V, t}\right)$ : Vector of the curtailed PV power amount of the grid nodes at time step $t$ in $p u$ (optimization variables).

$\left(\Delta p_{\text {Wind, },}\right)$ : Vector of the curtailed wind power amount of the grid nodes at time step $t$ in $p u$ (optimization variables).

$\left(q_{n, t}\right)$ : Vector of the original reactive power injection of the grid nodes at time step $t$ in $p u$.

$\left(\Delta q_{P V, t}\right)$ : Vector of the curtailed PV reactive power of the grid nodes at time step $t$ in $p u$ (optimization variables).

$\left(\Delta q_{\text {Wind,t }}\right)$ : Vector of the curtailed wind reactive power of the grid nodes at time step $t$ in $p u$ (optimization variables).

It is to be pointed out that the use of only line expansion in the planning algorithm, cannot fulfill the voltage constraints as the matrix $(A)$ and the vector $(C)$, used for the linearized LFC, are constant. To satisfy the voltage constraints, it is here necessary to control the injection power through the application of the BSS or DPC as in (23).

For reasons of simplicity, the current flow was approximated to the active current, assuming that the reactive current is relatively low as compared to the active current. Based on that, further linear constraints were implemented to ensure the compliance of the load flow with current-carrying capacities of the lines, using the linear Equation (14):

$$
\begin{gathered}
\text { If } b_{l, v}=1 \text {, then }:\left\{\begin{array}{l}
\left(g_{i j} \times\left(u_{i}-u_{j}\right)-b_{i j} \times\left(\vartheta_{i}-\vartheta_{j}\right)\right) \leq i_{\text {max }, l, v} \\
\left(g_{i j} \times\left(u_{i}-u_{j}\right)-b_{i j} \times\left(\vartheta_{i}-\vartheta_{j}\right)\right) \geq-i_{\text {max }, l, v}
\end{array}\right. \\
\forall l \in L, t \in T_{\text {year }, q, v \in\{0,1,2,3,4\}}
\end{gathered}
$$

$b_{l, v}$ : Boolean variable associated to the line $l$ and the expansion variant $v$ with $v \in\{0,1,2,3,4\}$ (optimization variable).

$i_{\text {max }, l, v}$ : Current-carrying capacity of line $l$ in case of grid expansion variant $v$ in $p u$.

The optimization variable $b_{l, v}$ is of Boolean type and can equal 0 or 1 at the end of the optimization. Each variable was associated to an expansion variant $v \in\{0,1,2,3,4\}$ and to a line $l \in N$, and indicates whether or not the line $l$ must be expanded according to the expansion variant $v$. The considered expansion variants are described in the Section 3.2.1. At the end of the optimization, the variable $b_{l, v}$ equals 1 if the expansion variable $v$ is part of the optimal grid reinforcement measures which lead to the least total costs. Otherwise, the variable $b_{l, v}$ equals 0 . The expansion variant $v=0$ represents the case where no expansion is required for the considered line. To ensure that for every line $l$ only one expansion variant among all considered variants is chosen by the optimization, a further constraint was implemented:

$$
\begin{gathered}
\sum_{v=0}^{N_{\text {var }}} b_{l, v}=1 \\
\forall l \in N, v \in\{0,1,2,3,4\}
\end{gathered}
$$

\subsubsection{Costs of the Grid Expansion}

The grid expansion variants considered in this work are as follows:

- Expansion variant 1: Expansion construction with a $361 \mathrm{~A}$ standard underground cable. If the existing line is a standard underground cable of $361 \mathrm{~A}$ current-carrying 
capacity, then a parallel cable with the same type is to be added, enabling a higher current-carrying capacity of $722 \mathrm{~A}$.

- Expansion variant 2: Replacement construction with a 361 A standard underground cable. The existing line is to be replaced by one $361 \mathrm{~A}$ standard underground cable.

- Expansion variant 3: Replacement construction with two 361 A standard underground cables. The existing line is to be replaced by two parallel $361 \mathrm{~A}$ standard underground cables, which enable a higher total current-carrying capacity of $722 \mathrm{~A}$.

- Expansion variant 4: Replacement construction with three $361 \mathrm{~A}$ standard underground cables. The existing line is to be replaced by three parallel $361 \mathrm{~A}$ standard underground cables, which enable a higher current-carrying capacity of $1083 \mathrm{~A}$.

The total costs of the grid expansion consist of the investments in new underground cables and feeder panels as well as the operating costs of the lines over the considered economic life:

$$
\operatorname{Cost}_{G E}=I_{G E, \text { line }}+I_{G E, \text { section }}+K_{G E, o p}
$$

$I_{G E, l i n e}$ : Investment costs in new lines in EUR million (optimization variable).

$I_{G E, \text { section: }}$ Investment costs in new feeder panels in EUR million (optimization variable).

$K_{G E, o p}$ : Total ongoing operating costs in EUR million (optimization variable).

The investment costs in new underground cables were calculated depending on the applied grid expansion variant $v$, its specific costs and the line length as follows:

$$
I_{G E, l i n e}=\sum_{l=1}^{N_{\text {lines }}} K_{\text {cable }} \times l_{l} \times\left(b_{l, 1}+b_{l, 2}+1.5 \times b_{l, 3}+2 \times b_{l, 4}\right)
$$

$K_{\text {cable }}$ : Specific costs of one cable $v$ in EUR $/ \mathrm{km}$.

$l_{l}$ : Length of the line $l$ in $\mathrm{km}$.

$N_{\text {lines }}$ : Number of the grid lines.

The addition of new feeder panels was considered only for expansion variants which increase the existing current-carrying capacity by at least $360 \mathrm{~A}$. The investment costs of new feeder panels were calculated depending on the applied expansion variant $v$ and the specific costs for new outgoing feeder panels.

$$
I_{G E, \text { section }}=\sum_{l=1}^{N_{\text {lines }}} K_{\text {section }} \times n_{T, l} \times\left(b_{l, 1}+b_{l, 3}+2 \times b_{l, 4}\right)
$$

$K_{\text {section: }}$ Specific investment costs of a new feeder panel in transformer stations EUR/unit.

$n_{T, l}$ : Number of feeder panels connected to the line $l$.

The annual operating costs, which comprise the inspection, the maintenance and repair costs of the new cables, were estimated at $2 \%$ of the total initial investment. The annual costs were then discounted over the economic life to the present value at the initial investment year:

$$
\begin{gathered}
K_{G E, O p}=2 \% \times\left(I_{G E, \text { line }}+I_{G E, s e c}\right) \times P V F \\
P V F=\frac{(1+r)^{N_{\text {years }}}-1}{r \times(1+r)^{N_{\text {years }}}}
\end{gathered}
$$

PVF: Present-value factor.

$r$ : Interest rate.

$N_{\text {years }}$ : Economic life considered in $y r$.

Table 6 shows the specific costs of the adopted standard grid expansion measures for the reinforcement of MV grids in this work. 
Table 6. Specific costs of the adopted standard grid expansion measures for MV grids [1].

\begin{tabular}{|c|c|c|}
\hline Equipment & Description & Specific Costs \\
\hline One underground cable $361 \mathrm{~A}$ & $\begin{array}{l}\text { Cable, ground work, land, } \\
\text { resonant neutral earthing }\end{array}$ & 145 TEUR/ km \\
\hline One outgoing feeder panel361 A & $\begin{array}{l}\text { Busbar (partly), coupling section, } \\
\text { feeder panel, secondary system, land }\end{array}$ & 90 TEUR/unit \\
\hline
\end{tabular}

\subsubsection{Costs of the BSS Application}

The total costs of the BSS consist of the initial investment in the BSS project, the replacement costs of battery cells and converters at their end of life, as well as the operating costs of battery systems over the considered economic life:

$$
\operatorname{Cost}_{B S S}=I_{B S S, i n i}+K_{B S S, o p}+I_{B S S, r e p}
$$

$I_{B S S, \text { ini }}$ : Initial investment costs in the BSS project in EUR million (optimization variable).

$K_{B S S, o p}$ : Total operating costs of the BSS in EUR million (optimization variable).

$I_{B S S, \text { rep }}$ : Replacement investment in battery cells and converters in EUR million (optimization variable).

The initial investment in the BSS project involve the capacity-specific expenses such as the costs of battery cells, connectors, battery monitoring systems, sensors, housing, shelves. The investment costs include also the power-specific costs such as the costs of inverters and circuit breakers. They cover, furthermore, the installation and land costs. The specific investment costs were deduced from the total costs of existing large scaled lithium-ion battery projects in Germany and worldwide divided by the total capacity of the battery system. The initial investment in the BSS was hence calculated in the planning algorithm based on the specific investment costs and the total capacity of the BSS:

$$
I_{B S S, \text { ini }}=K_{B S S, \text { spec }} \times \sum_{s=1}^{N_{\text {nodes }}} E_{\text {max }, S}
$$

$E_{\text {max }, s}:$ Capacity of the BSS $s$ in $M W h$ (optimization variable).

$K_{B S S, \text { spec: }}$ Specific investment costs in BSS projects in EUR/MWh.

The replacement of components such battery cells and new converters are due at their end of life. In this work, the replacement investments of battery cells and converters were considered in the optimization as follows:

$$
\begin{gathered}
I_{\text {rep }, \text { batt }}=\sum_{i=1}^{N_{\text {rep }, \text { Batt }}} \frac{K_{\text {batt }, i} \times \sum_{s=1}^{N_{\text {nodes }}} E_{\text {max }, s}}{(1+r)^{i \cdot N_{\text {life }, \text { batt }}}} \\
I_{\text {rep,conv }}=\sum_{i=1}^{N_{\text {rep }, \text { Conv }}} \frac{K_{\text {conv }, i} \times \sum_{s=1}^{N_{\text {nodes }}} P_{\text {max }, \text { s }}}{(1+r)^{i \cdot N_{\text {life,conv }}}} \\
I_{\text {BSS,rep }}=I_{\text {rep,Batt }}+I_{\text {rep }, \text { Conv }}
\end{gathered}
$$

$I_{\text {rep,batt }}$ : Replacement investment in battery cells in EUR million (optimization variable). $I_{\text {rep,conv }}$ : Replacement investment in converters in EUR million (optimization variable). $K_{b a t t, i}:$ Specific costs of battery cells at the time of the investment $i$ in EUR/MWh.

$K_{\text {conv }, i}$ : Specific costs of converters at the time of the investment $i$ in EUR/MW.

$P_{\max , s}$ : Rated power of the BSS $s$ in $M W$ (optimization variable).

$N_{\text {life,batt }}$ : Service life of battery cells in $y r$.

$N_{\text {life,conv }}$ : Service life of converters in $y r$.

$N_{\text {rep,batt }}$ : Count of required replacements of battery cells.

$N_{\text {rep,conv }}$ : Count of required replacements of converters. 
The annual operating costs of the BSS were estimated at $0.5 \%$ of the initial investment costs [23], and discounted to the total present value of the operating costs at the initial investment year:

$$
K_{B S S, o p}=0.5 \% \times I_{B S S, i n i} \times P V F
$$

Table 7 presents the applied specific expenses for the calculation of the total occurring BSS costs. The adopted investment costs for big battery plants were thereby determined as the average of the specific cost values of existing stationary battery projects [24-29].

Table 7. Specific investment costs of BSS projects, battery cells and converters.

\begin{tabular}{cc}
\hline Investment Type & Specific Costs \\
\hline Investment costs for big stationary battery plants & $489 \mathrm{EUR} / \mathrm{kWh}[24-29]$ \\
Replacement investments in battery cells & $70 \mathrm{EUR} / \mathrm{kWh}[30]$ \\
Replacement investments in converters & $65 \mathrm{EUR} / \mathrm{kW} \mathrm{[31]}$ \\
\hline
\end{tabular}

Table 8 illustrates the adopted input data, including the technical parameter of the BSS, for the calculation of the total BSS costs over the considered economic time of 40 years.

Table 8. Adopted assumptions for the cost calculation of BSS.

\begin{tabular}{cc}
\hline Input Data & Specific Costs \\
\hline Efficiency factor of the battery system & $90 \%$ [32] \\
Depth of discharge (DoD) & $100 \%$ [33] \\
Service life of battery cells & $20 \mathrm{a}[34]$ \\
Service life of converters & $15 \mathrm{a}[35]$ \\
Economic life & $40 \mathrm{a}[36]$ \\
Interest rate & $8 \%$ \\
\hline
\end{tabular}

\subsubsection{Costs of the DPC Application}

The costs of the DPC represent the compensation costs for the curtailment of RES power by the grid operator. This implies the remote control of the RES by grid operators. In this work, it was assumed that all connected PV and wind plants into the grid are remote controllable by the responsible grid operators. Besides, the accruing curtailed energy over the simulated year was assumed as constant over the considered economic life. The total costs of the DPC over the economic life were hence calculated based on the yearly curtailed energy, the specific curtailment costs and the present-value factor:

$$
\text { Cost }_{D P C}=K_{D P C, \text { spec }} \times E_{D P C} \times P V F
$$

$E_{D P C}$ : Total curtailed energy during the simulated year in $M W h / a$ (optimization variable).

$K_{D P C, \text { spec }}$ : Specific costs of the power curtailment in EUR/MWh.

The accruing curtailed energy over the simulated year was calculated depending on the curtailed PV and wind power amount at every time step and for every node of the grid:

$$
E_{D P C}=\sum_{t=1}^{N_{\text {steps }}} \sum_{i=1}^{N_{\text {nodes }}}\left(\Delta P_{P V, i, t}+\Delta P_{\text {Wind }, i, t}\right) \times \Delta t_{\text {step }}
$$

$\Delta P_{P V, i, t}:$ Curtailed PV active power on node $i$, at time step $t$ in MW (optimization variable). variable).

$\Delta P_{\text {Wind, } i, t}:$ Curtailed wind active power on node $i$ at time step $t$ in MW (optimization

$\Delta t_{\text {step: }}$ : Duration of a time step $t$ in $h$.

Table 9 presents the assumed compensation costs for the curtailment of RES power in this work. 
Table 9. Adopted specific costs for the curtailment of RES power.

\begin{tabular}{cc}
\hline Cost Type & Specific Costs \\
\hline Compensation costs for the curtailment of RES power & 97.2 EUR/MWh [37] \\
\hline
\end{tabular}

\section{Results of the Grid Planning}

In this section, the results of the classical grid planning and of the proposed new planning method are described.

\subsection{Results of the Classical Grid Planning}

In a first step, the MV grid was analyzed before application of any reinforcement or expansion measures. For that, two extreme load and generation scenarios HLLG and LLHG according to Section 2.1 were considered. Since the $(n-1)$ was not considered in this work, neither in the classical grid planning nor in the new planning method, the loading of the grid equipment was limited to $100 \%$ of its current-carrying capacity for both HLLG and LLHG case scenarios. The linearized load flow calculation, described in Section 3.1.3, was applied to calculate the voltage magnitudes on the nodes and the loading of the lines.

Figure 5 presents in the form of boxplots the resulting voltage magnitude on the grid nodes which showed voltage limit transgressions. The boxplots indicate the voltage magnitude of the nodes for 25,50 and $75 \%$ of the calculated states, as well as the minimum and maximum reached voltage values. The dotted red lines illustrate the maximum and minimum permitted voltage limits. As shown in the figure, the voltage magnitude on several nodes of the grid is below the lower voltage limit of $0.985 \mathrm{pu}$. This is due to the extreme adopted HLLG case scenario, which assumes a load demand equivalent to $100 \%$ of the connected load capacity and $0 \%$ renewable feed-in power. This scenario is very conservative and unlikely to occur in the reality. Node 5 represents the node, on which wind plants are connected. The voltage magnitude on this node exceeds the $+5 \%$ limit subject to the nominal voltage due to the high feed-in power in the LLHG case scenario.

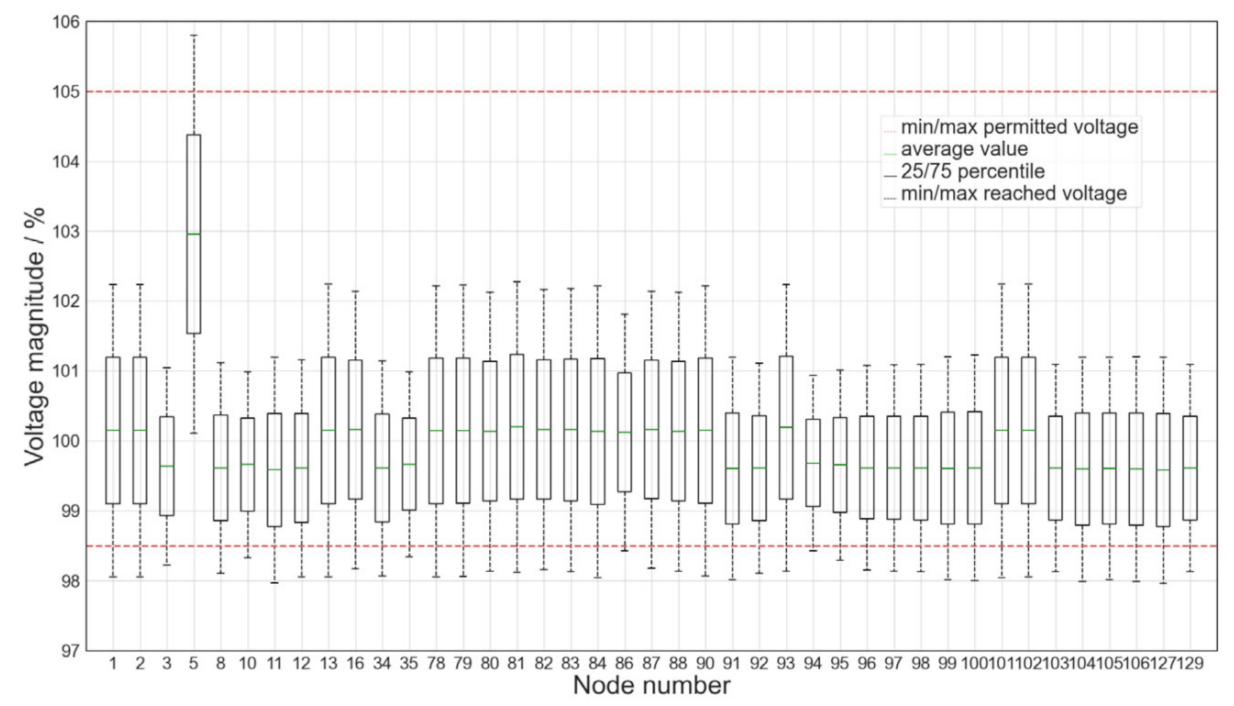

Figure 5. Voltage magnitude on some nodes of the MV grid before grid reinforcement.

Figure 6 shows the power loading of the overloaded lines in the grid, in the form of boxplots. The boxplots illustrate for each line the loading values for 25,50 and $75 \%$ of the total calculated states as well as the minimum and maximum reached loading values. The dotted red line illustrates the power-carrying capacity of the lines in percent. As demonstrated through the figure, the power flow through lines 79, 82 and 83 reaches about $110 \%$ of their current-carrying capacities. Line 6 , which connects the wind power plants to 
the HV/MV substation shows also a small overload. A reinforcement of the grid is hence required to prevent the determined congestion.

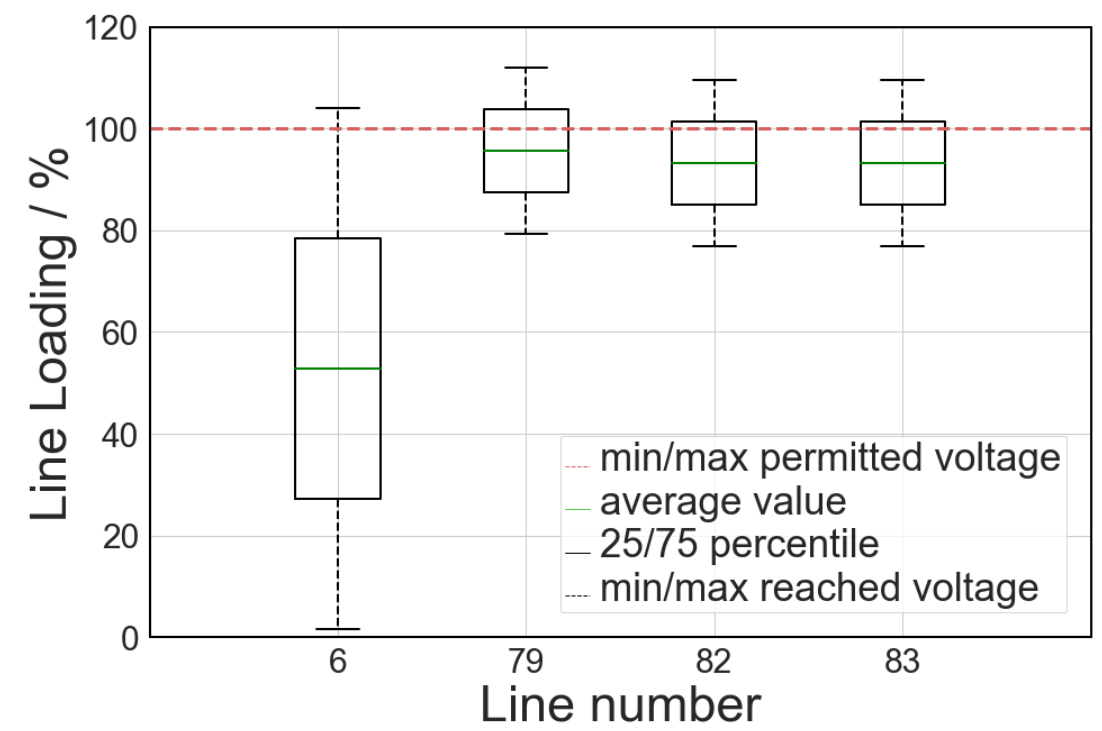

Figure 6. Line loading on some lines of the MV grid before grid reinforcement.

In a further step, the described classical grid planning method in Section 2 was applied on the modeled MV grid. As a first remedy measure to the determined grid congestion above, the voltage at the $20 \mathrm{kV}$ busbar was adjusted to shift the voltage magnitudes on the grid nodes above the lower voltage limit. For that, the voltage setpoint of the HV /MV transformer on the MV side was increased by $2 \%$ of the nominal voltage in the HLLG case scenario. The adjustment of the voltage setpoint at the $20 \mathrm{kV}$ busbar enabled the compliance of the voltage magnitudes with the specified limits in the HLLG case scenario. As shown in Figure 7, all transgressions of the lower voltage limit were hence completely prevented. However, the voltage transgression of the upper voltage limit on node 5 cannot be prevented by decreasing the voltage setpoint of the HV/MV transformer since this would lead to the voltage transgression of the lower voltage limit on other nodes of the grid. The voltage congestion on node 5 must be hence treated through further grid reinforcement measures.

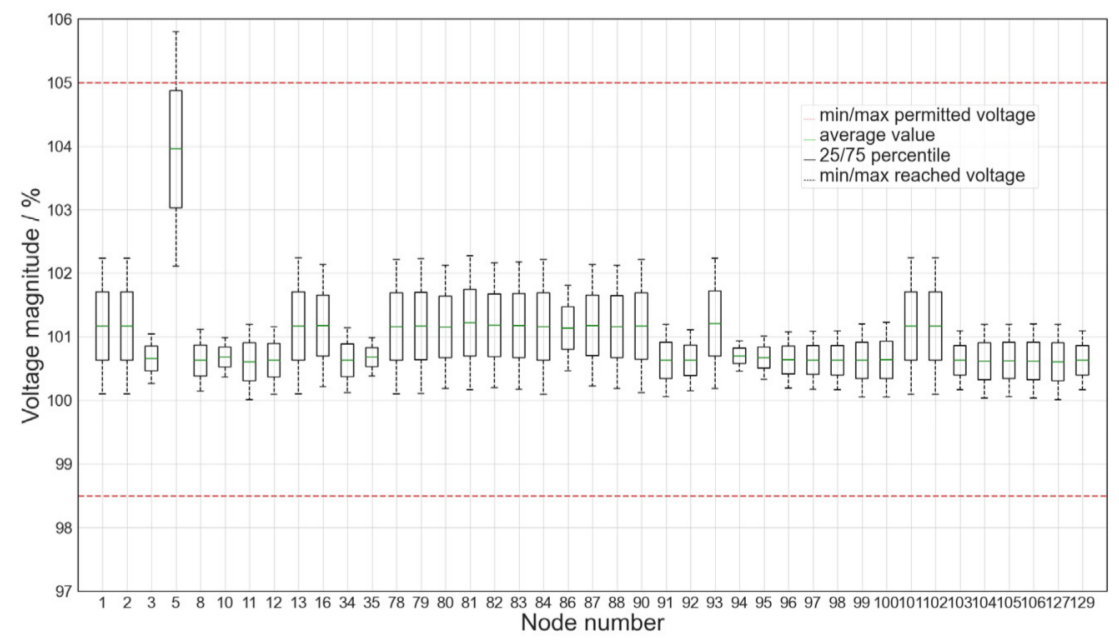

Figure 7. Voltage magnitude on some nodes of the MV grid after optimizing the voltage setpoint of the $\mathrm{HV} / \mathrm{MV}$ transformer. 
As illustrated through Figure 8, the overloading of the lines could not be prevented through the adjustment of the HV/MV transformer setpoint. Therefore, further expansion measures are still required.

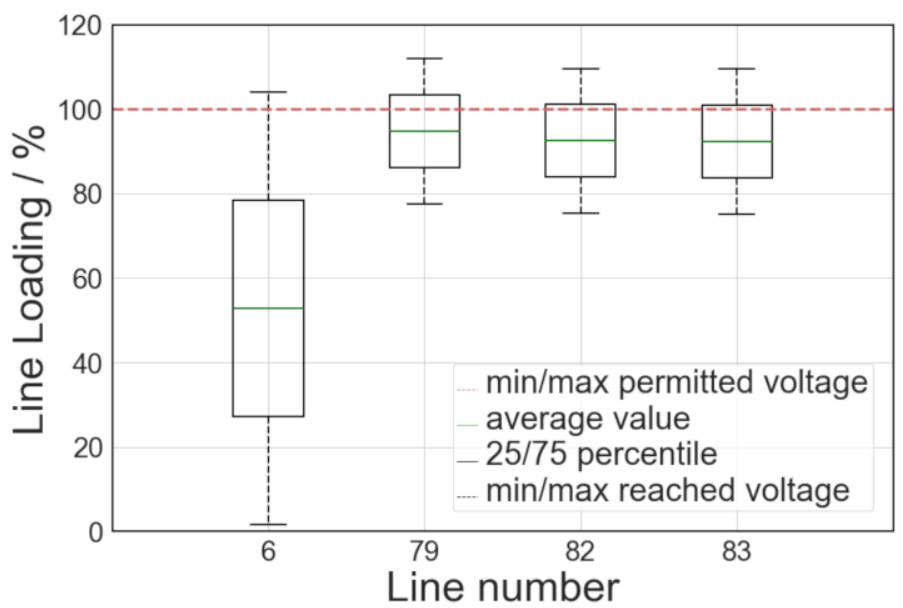

Figure 8. Line loading on some lines of the MV grid after optimizing the voltage setpoint of the $\mathrm{HV} / \mathrm{MV}$ transformer.

For reasons of simplicity, only standard network components as presented in Table 3 were considered for the grid expansion. The iterative proceeding according to Figure 3 was applied to determine the required grid expansion measures that can remedy the remaining grid congestion of Figures 7 and 8 . Table 10 presents the resulting expansion measures. In order to reduce the loading on line 6 below its 100\% current-carrying capacity, line 6 was replaced by two parallel $361 \mathrm{~A}$, enabling hence a current-carrying capacity of $722 \mathrm{~A}$. In addition, to remedy the overloads on lines 79,82 and 83 , they were replaced by a $361 \mathrm{~A}$ cable each.

Table 10. Results of the grid expansion within the classical grid planning.

\begin{tabular}{cccc}
\hline Line & Length/km & Initial Current Capacity & Grid Expansion Variant \\
\hline Line 6 & 13.8 & $537 \mathrm{~A}$ & $2 \times 361$ A cable \\
Line 79 & 0.253 & $175 \mathrm{~A}$ & $1 \times 361$ A cable \\
Line 82 & 0.498 & $175 \mathrm{~A}$ & $1 \times 361$ A cable \\
Line 83 & 0.456 & $175 \mathrm{~A}$ & $1 \times 361$ A cable \\
\hline
\end{tabular}

Figure 9 shows the resulting voltage magnitudes on the grid nodes after optimizing the voltage setpoint of the HV/MV transformer and after grid expansion. The voltage magnitude on node 5 in the LLHG case scenario has been now reduced below the $5 \%$ limit due to the expansion of line 6.

The loading of the lines in the grid for both HLLG and LLHG case scenarios is now beneath the $100 \%$ current-carrying capacity of the lines, as illustrated through Figure 10.

After determining the required grid expansion measures, the total costs of the expansion measures were calculated based on the described approach in Section 3.2.1. However, the costs were not calculated here within a cost optimization, since the expansion measures were here already set. The total costs of the grid expansion amount to EUR 4.05 million. As presented in Table 11, about $81 \%$ of the total costs are due to the investment costs in the new cables and feeder panels (CAPEX). About 19\% are due to the ongoing inspection, maintenance and repair costs (OPEX). 


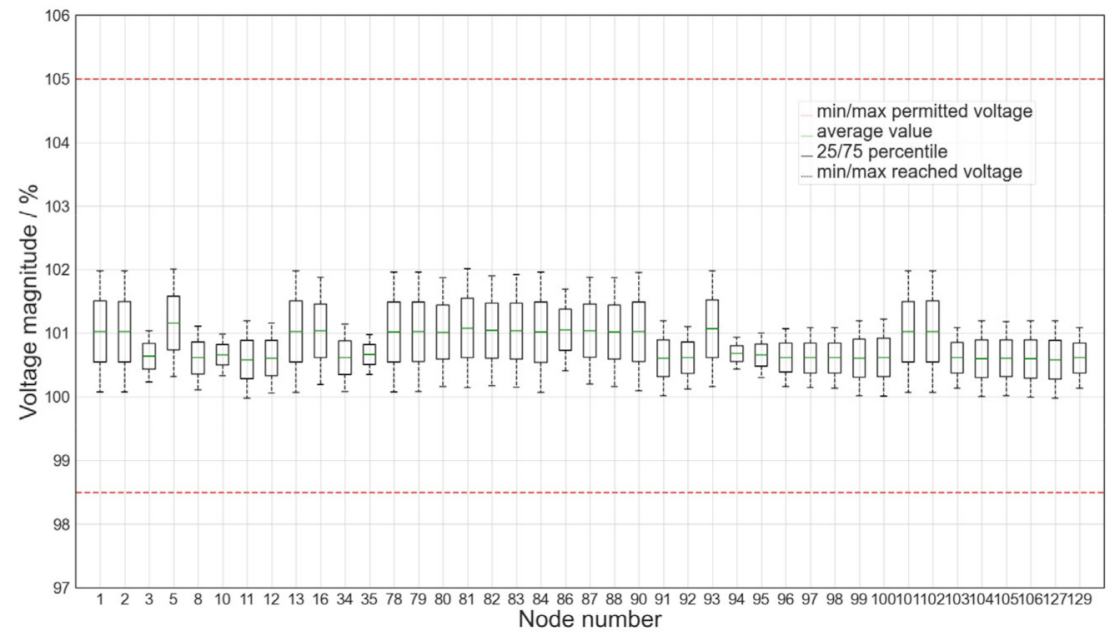

Figure 9. Voltage magnitude on some nodes of the MV grid after optimizing the voltage setpoint of the $\mathrm{HV} / \mathrm{MV}$ transformer and after grid expansion.

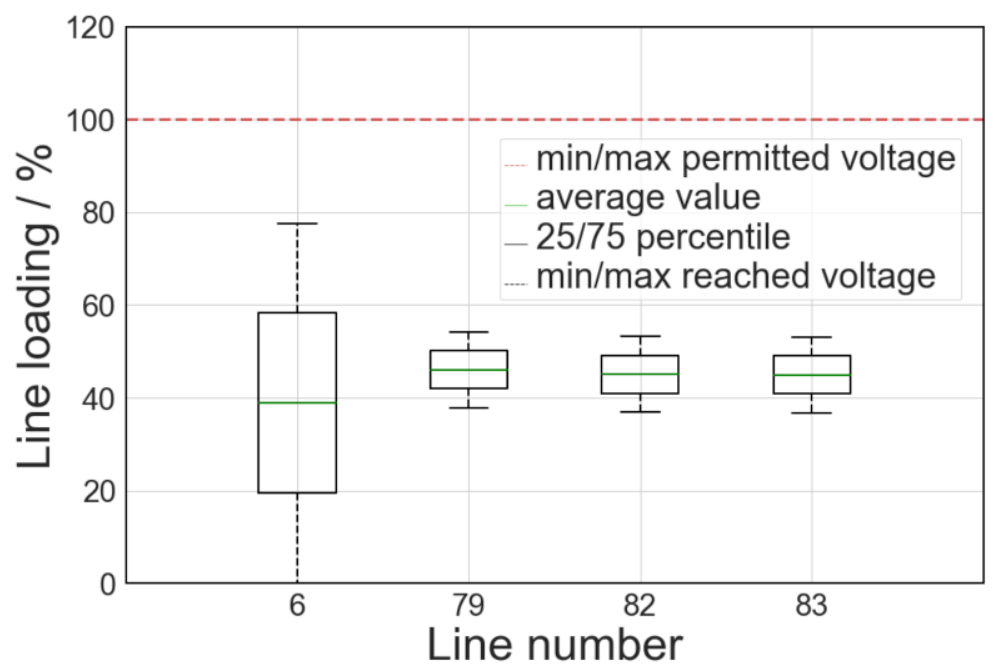

Figure 10. Line loading on the initially overloaded lines of the MV grid after optimizing the voltage setpoint of the $\mathrm{HV} / \mathrm{MV}$ transformer and after grid expansion.

Table 11. Results of the planning variant with underground cables.

\begin{tabular}{cccc}
\hline $\begin{array}{c}\text { Total Costs/EUR } \\
\text { Million }\end{array}$ & $\begin{array}{c}\text { Investment in } \\
\text { Cables/\% }\end{array}$ & $\begin{array}{c}\text { Investment in } \\
\text { Feeder Panels/\% }\end{array}$ & Operating Costs/\% \\
\hline 4.1 & 78.5 & 2.2 & 19.3 \\
\hline
\end{tabular}

\subsection{Results of the Planning Algorithm}

In order to verify the potential of the planning algorithm, which is proposed in this work as alternative planning approach to the classical method the MV grid was analyzed, in a first step without any grid reinforcement. For that, the linearized load flow calculation, described in the Section 3.1.3 was applied to calculate the voltage magnitudes on the nodes and the line loading of the lines over one year with $15 \mathrm{~min}$ time resolution. Figure 11 presents in the form of boxplots the voltage magnitude on the node 5 which shows voltage congestion and on the $20 \mathrm{kV}$ busbar (node 15). The voltage magnitude on node 5 exceeds the $+5 \%$ limit subject to the nominal voltage. Figure 12 shows the loading on the overloaded lines in the grid, in the form of boxplots. As demonstrated through the figure, at certain time points of the simulated year, the power flow through lines 79, 82, and 83 reaches about $125 \%$ of their thermal capacities. The line 6 , which connects the wind power plants to the 
MV substation shows also a small overload at certain time points of the simulated year. A reinforcement of the grid is hence required to prevent the determined congestion.

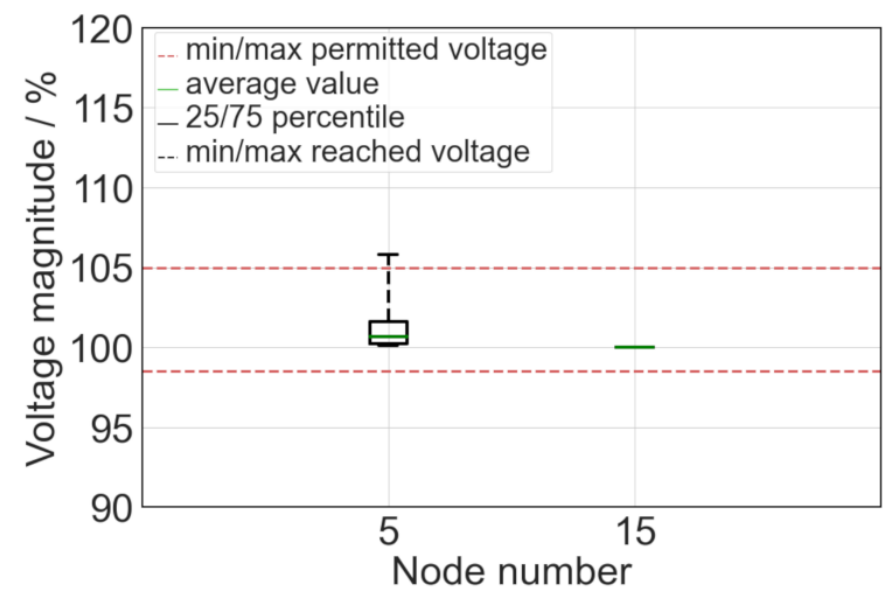

Figure 11. Voltage magnitude on some nodes of the MV grid.

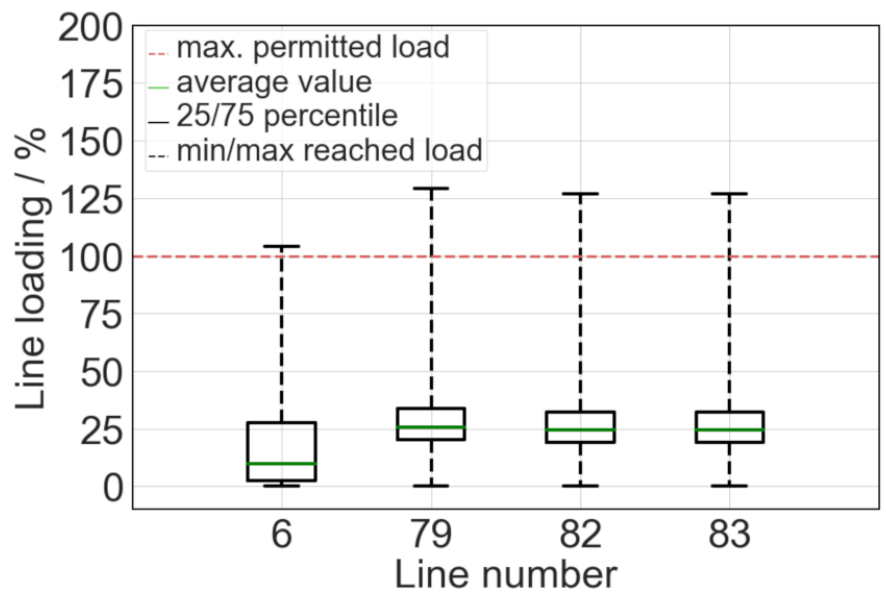

Figure 12. Line loading on the overloaded lines of the MV grid.

In a second step, the planning algorithm, described in Section 3.2, was applied on the MV grid in order to reinforce it, by means of grid expansion, BSS and DPC at minimal cost. In what follows a description of the planning results of the MV grid for different planning variants.

\subsubsection{Planning Results in Case of Underground Cable Application}

The presented planning algorithm in this work enables the compliance of the voltage magnitude with the permitted voltage limits only through the variation of the power injection. The voltage constraints (23) were, therefore, omitted for this planning variant. The constraints (24) which aim at the prevention of line overloads, through the control of power injection or the increase of the current carrying capacity of the lines, were, however, considered. Table 12 shows the optimal expansion measures, resulting from the planning algorithm. As shown in the table, line 6 which connects the wind power plants to the main substation and had initially a current-carrying capacity of $537 \mathrm{~A}$, was replaced through two parallel cables of $361 \mathrm{~A}$ each, according to the expansion variant 3 . The lines 79, 82 and 83 which had initially a current-carrying capacity of $175 \mathrm{~A}$ each, were replaced through a 361 A cable each, according the expansion variety 2. 
Table 12. Results of the planning variant with underground cables.

\begin{tabular}{ccc}
\hline Line & Length/km & Grid Expansion Variant \\
\hline Line 6 & 13.8 & $2 \times 361$ A cable \\
Line 79 & 0.253 & $1 \times 361$ A cable \\
Line 82 & 0.456 & $1 \times 361$ A cable \\
Line 83 & 0.498 & $1 \times 361$ A cable \\
\hline
\end{tabular}

The total costs of this planning variant amount to EUR 4.05 million. As presented in Table 13, about $81 \%$ of the total costs are due to the investment costs in the new cables and feeder panels (CAPEX). About 19\% are due to the ongoing inspection, maintenance and repair costs (OPEX).

Table 13. Results of the planning variant with underground cables.

\begin{tabular}{cccc}
\hline $\begin{array}{c}\text { Total Costs/EUR } \\
\text { Million }\end{array}$ & $\begin{array}{c}\text { Investment in } \\
\text { Cables/\% }\end{array}$ & $\begin{array}{c}\text { Investment in } \\
\text { Feeder Panels/\% }\end{array}$ & Operating Costs/\% \\
\hline 4.05 & 78.5 & 2.2 & 19.3 \\
\hline
\end{tabular}

Figure 13 shows the current flow through line 6 initially (blue trace) and after grid expansion (green trace). Both traces are identical, since the injection power of the wind plants was not changed. The current-carrying capacity however was increased from $537 \mathrm{~A}$ (dotted red trace) to $722 \mathrm{~A}$ (dotted purple trace).

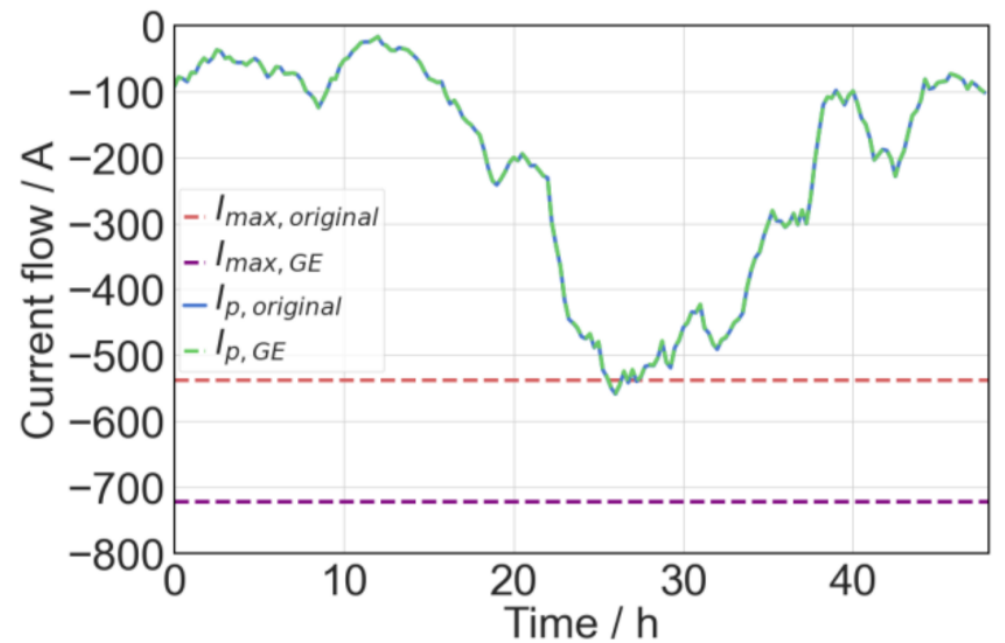

Figure 13. Current flow through the line 6 initially (blue trace) and after grid expansion (green trace).

\subsubsection{Planning Results in Case of BSS Application}

In case of BSS application, two BSS with a 12.2 MWh total capacity and 4.5 MW rated power are required to prevent all prognosticated grid congestions. Table 14 presents the placement and the dimensioning of the BSS.

Table 14. Results of the planning variant BSS.

\begin{tabular}{ccc}
\hline Placement & Capacity $\backslash$ MWh & Rated Power/MW \\
\hline Node 5 & 6.3 & 2.7 \\
Node 87 & 5.9 & 1.8 \\
\hline
\end{tabular}

The costs of the planning variety using BSS as only grid reinforcement measures amount to EUR 6.6 million. Table 15 shows the cost allocation between initial investment costs, replacement costs and operating costs. 
Table 15. Results of the planning variant with BSS.

\begin{tabular}{cccc}
\hline $\begin{array}{c}\text { Total Costs/EUR } \\
\text { Million }\end{array}$ & Initial Investment/\% & $\begin{array}{c}\text { Replacement } \\
\text { Investment/\% }\end{array}$ & Operating Costs/\% \\
\hline 6.6 & 90 & 4.6 & 5.4 \\
\hline
\end{tabular}

According to this planning variety, the existing power lines were maintained and the current-carrying capacity of the lines was not increased. Instead, BSS were applied on nodes 5 and 87 to charge the surplus power when the power injection of RES is higher than current-carrying capacities of the lines and discharge the stored energy into the grid when the injection power decreases. Figure 14 shows the injection power of the wind plants initially (blue trace) and after application of the BSS (green trace) for two exemplary days of the simulated year. The figure illustrates here the contribution of the BSS in shaving high power injection peaks. Figure 15 presents the charging and discharging power of the BSS (blue trace), as well as the stored energy (orange trace) for the considered days.

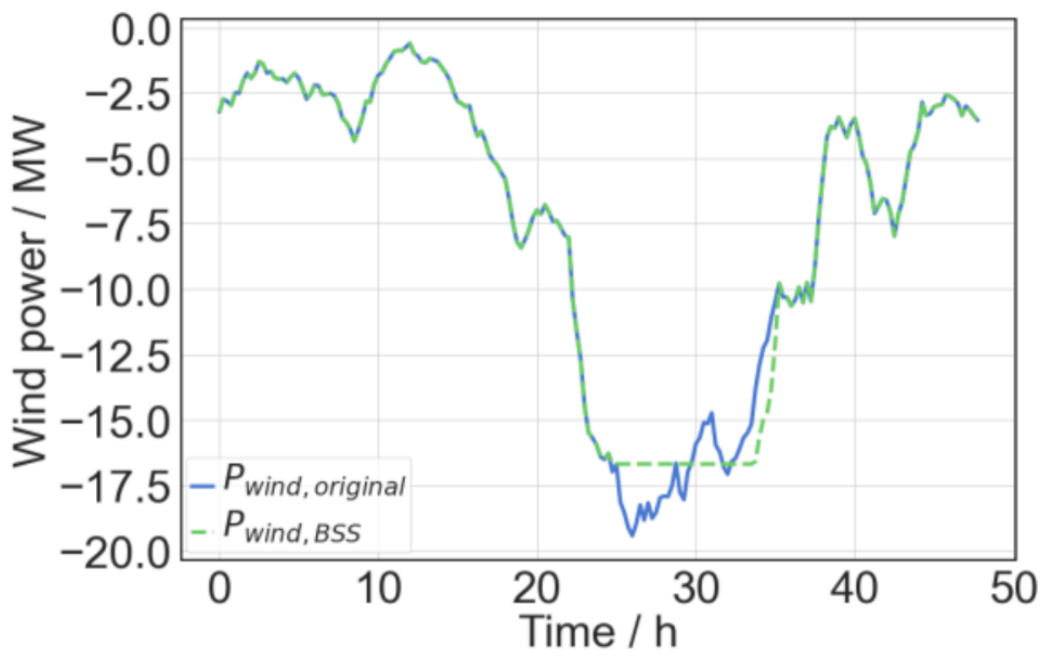

Figure 14. Injection power of the wind plants initially (blue trace) and after application of the BSS (green trace).

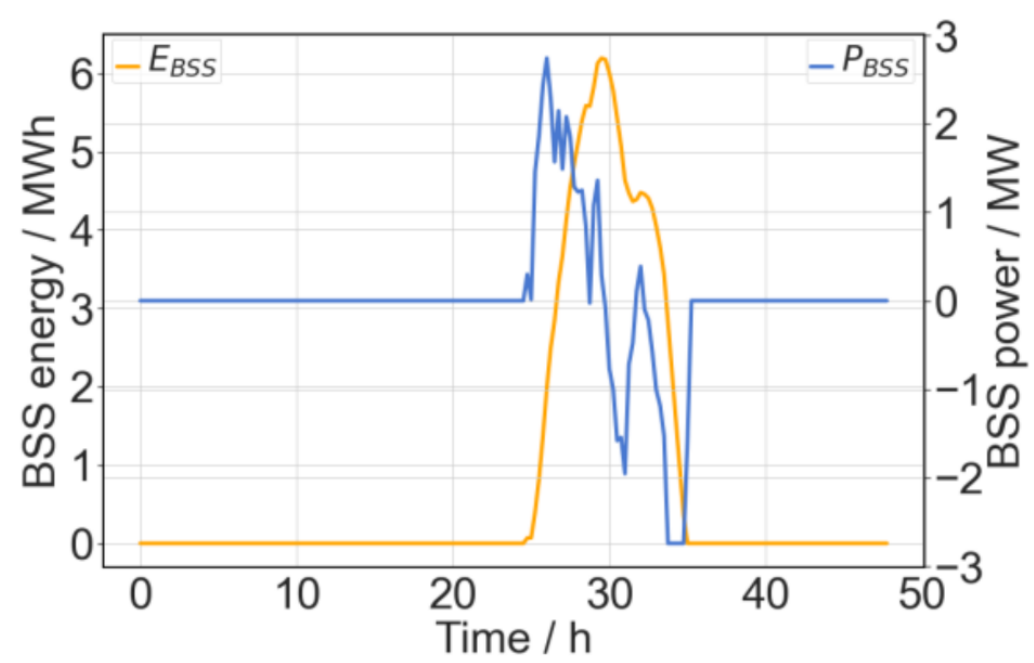

Figure 15. Charging and discharging power (blue trace) and stored energy of the BSS (orange trace).

As demonstrated through Figure 16, the control of the injection power on node 5 through the application of BSS led to the compliance of the voltage magnitude with the maximal permitted voltage limit (green trace). The current flow through line 6 was 
also maintained within the current-carrying capacity of the line (green trace), as shown in Figure 17.

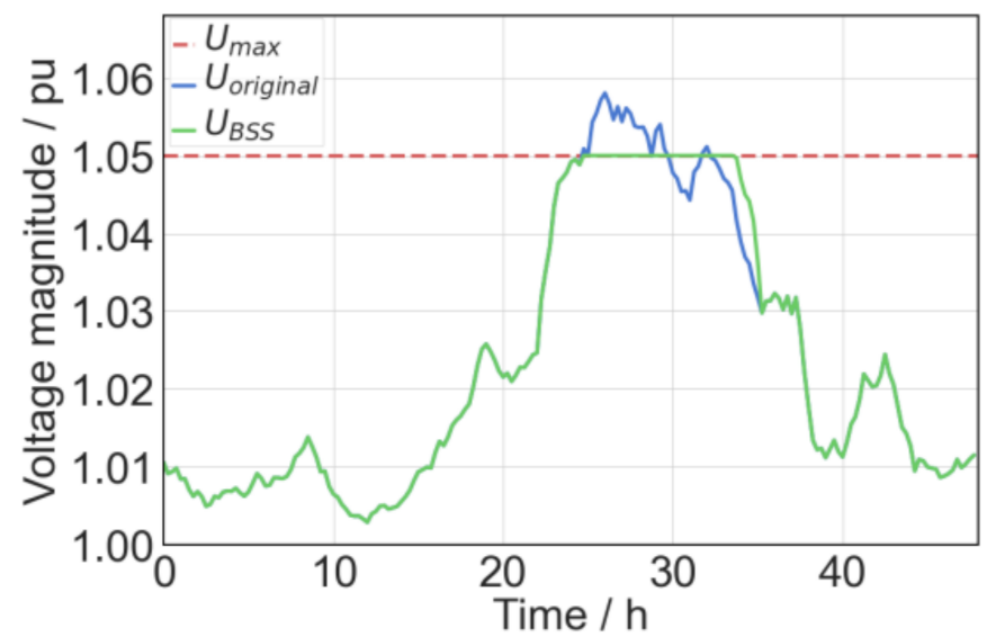

Figure 16. Voltage magnitude on node 5, initially (blue trace) and after application of BSS (green trace).

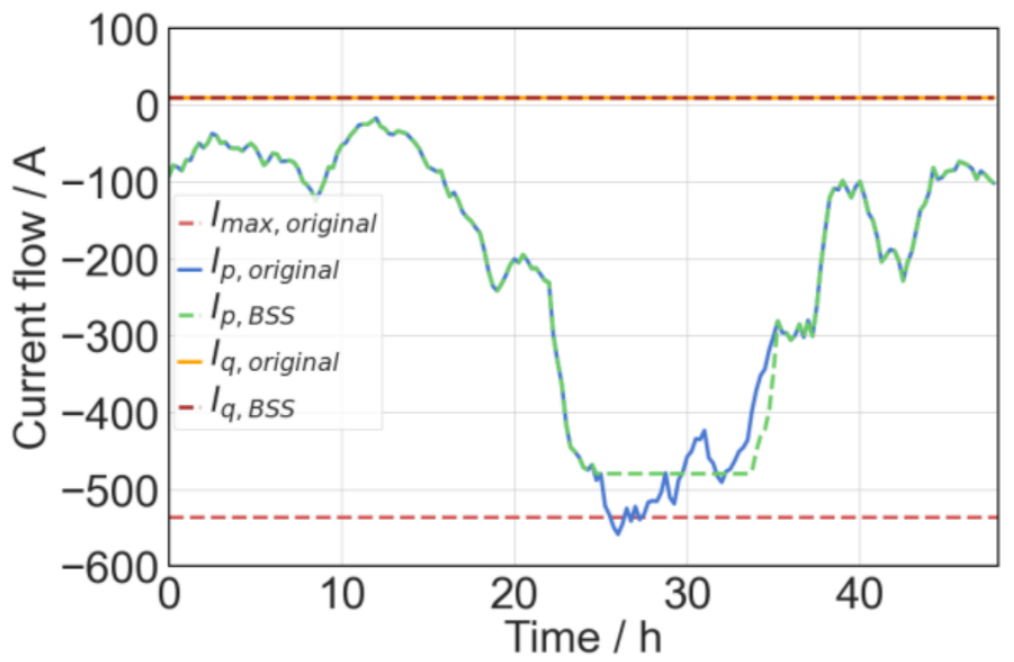

Figure 17. Current flow through line 6 before (blue trace) and after BSS application (green trace).

\subsubsection{Planning Results in Case of DPC Application}

The application of DPC in the grid planning can be, depending on the considered grid and the RES scenario, insufficient to prevent all prognosticated congestions. Due to the infrequent and relatively limited congestions of the considered MV grid in this work, the DPC application has proven to be sufficient to prevent these congestions. For that, a total energy amount of $46.9 \mathrm{MWh}$ was curtailed during the simulated year, as presented in Table 16. The use of DPC in the planning algorithm assumes thereby the controllability of all PV and wind plants connected to the grid by the responsible grid operator.

Table 16. Results of the planning variant dynamic curtailment.

\begin{tabular}{ccc}
\hline Plants & Prognosticated Energy/GWh/a & Curtailed Energy/MWh/a \\
\hline PV & 38.9 & 30.1 \\
Wind & 29.1 & 16.8 \\
\hline
\end{tabular}

As shown in Table 17, the total costs of the DPC planning variant over the considered economic life amount to EUR 0.054 million. The yearly curtailed energy amount and the 
specific costs of the power curtailment were here assumed as constant over the economic life, as described in Section 3.2.3.

Table 17. Resulting costs of the dynamic curtailment variant.

\begin{tabular}{c}
\hline Total Costs/EUR Million \\
\hline 0.054 \\
\hline
\end{tabular}

The same as by the application of BSS, the use of DPC for peak shaving enables the prevention of the grid congestion. Figures 18 and 19 show the contribution of the DPC to the compliance of the voltage magnitude with the permitted maximal limit as well as to the compliance of the current flow with the current-carrying capacities of the existing lines, respectively. The difference to the BSS application resides here in the fact that the curtailed RES power is definitively unexploited.

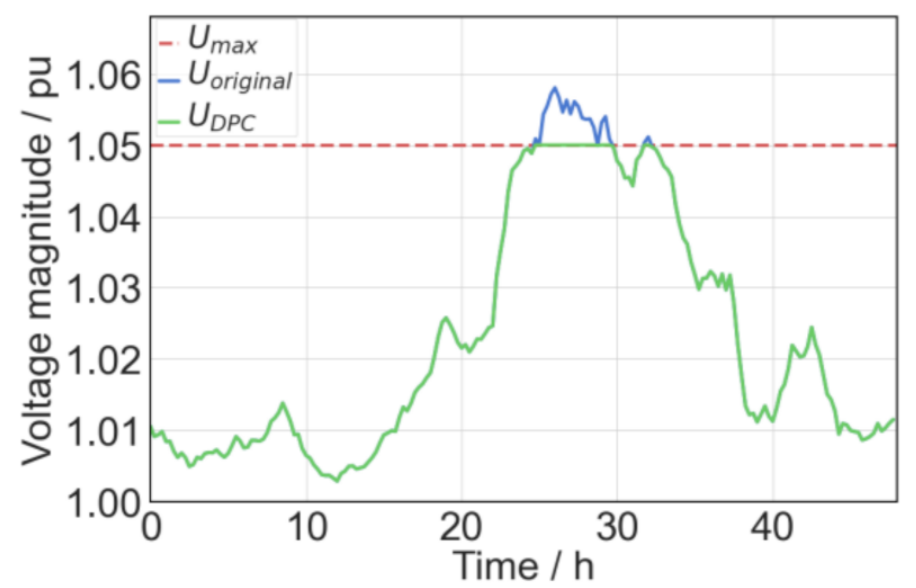

Figure 18. Voltage magnitude on node 5, initially (blue trace) and after application of DPC (green trace).

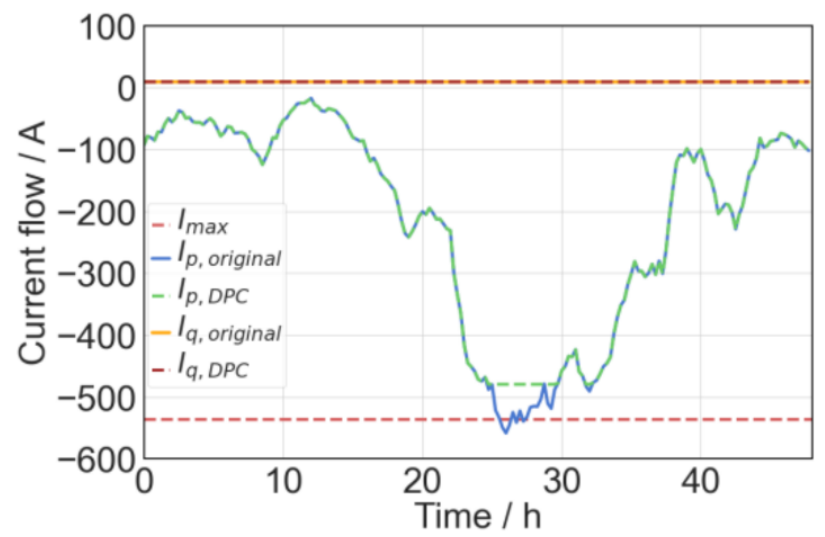

Figure 19. Current flow through line 6 before (blue trace) and after DPC application (green trace).

\subsubsection{Planning Results in Case of Underground Cable and BSS Application}

The planning algorithm was further applied for a planning variant which enables a combined use of underground cables and BSS to prevent grid congestion. Tables 18 and 19 present the resulting optimal reinforcement measures that ensure minimal total costs. The reinforcement measures comprise one BSS on node 5 and the replacement of lines 79, 82 and 83 through a new 361 A cable each. 
Table 18. Results of the BSS dimensioning for the planning variant combining underground cables and BSS.

\begin{tabular}{ccc}
\hline Placement & Capacity/MWh & Rated Power/MW \\
\hline Node 5 & 6.3 & 2.7 \\
\hline
\end{tabular}

Table 19. Results of the cable dimensioning for the planning variant combining underground cables and BSS.

\begin{tabular}{ccc}
\hline Line & Length/km & Grid Expansion Variant \\
\hline Line 79 & 0.253 & 2 \\
Line 82 & 0.456 & 2 \\
Line 83 & 0.498 & 2 \\
\hline
\end{tabular}

The total costs of this variant over the considered economic life amount to EUR 3.65 million. Table 20 presents the cost allocation between BSS and cables, where the costs of the BSS make up about $94 \%$ of the total costs.

Table 20. Resulting costs of the BSS and grid expansion variant.

\begin{tabular}{cc}
\hline Total Costs/EUR Million & 3.65 \\
\hline BSS investment/\% & 84.4 \\
Replacement investment/\% & 4.6 \\
BSS operating costs $\%$ & 5 \\
Investment in cables $\%$ & 4.8 \\
Investment in feeder panels/\% & 0 \\
Cable operating costs $/ \%$ & 1.2 \\
\hline
\end{tabular}

\section{Discussion}

The comparison of the results of the planning algorithm with the results of the classical planning method shows that the classical planning does not always reflect realistic and specific load and generation scenarios of the region. The considered HLLG case scenario is unlikely to occur and leads to low voltage magnitudes on several nodes of the grid. On the other hand, the LLHG case scenario leads to lower loading values as compared with the results of the planning algorithm which indicates that this case scenario does not reflect the most conservative and yet likely reverse power flow scenario. Consequently, planning the grid based on these two scenarios could lead to an overdimensioning or an underdimensioning of the grid. The proposed planning algorithm uses, however, specific time series for load and generation which approximates the load and generation scenarios that are most likely to occur in the region.

In the case of the considered MV system, the total grid reinforcement costs resulting from the classical planning are equivalent to the resulting costs from the planning algorithm in the case that only underground cables are applied. The resulting costs could however differ in the case of other MV systems. Since the cost calculation of the grid expansion measures is not included in the grid planning proceeding, a cost optimized planning of the grid cannot be always guaranteed. Especially in the case of different used types of grid reinforcement instruments such as grid expansion, BSS and PC, a decision about which, where and how many grid reinforcement measures should be applied to prevent the grid congestion is hard to achieve at minimal costs based on the classical planning method. The application of the planning algorithm could be here advantageous in order to determine the optimal combination and dimensioning of the reinforcement measures which lead to the minimal grid planning costs.

From the results of the planning algorithm, it appears that the application of the DPC is the most economical planning variant for the considered MV grid. The curtailment of the $\mathrm{PV}$ and wind power plants subject to the $3 \%$ curtailment limit has proven to be sufficient 
to prevent all forecasted line overloads and voltage limit violations. This is mainly due to the infrequent and limited prognosticated congestions in this case. The application of the DPC implies, however, that the curtailed power will be definitively wasted.

The combined use of BSS and underground cables in the considered MV grid has shown to be a more economical planning solution than the use of BSS or underground cables individually. In this case, the three lines of the grids 2, 3 and 4 have been replaced by cables with higher current-carrying capacity to prevent overloads and one BSS has been applied on the connection node of the wind plants to prevent voltage transgressions and the overload of the connecting line 6 . Unlike line 6 , relatively high overloads have been prognosticated on lines 79, 82 and 83. Besides, line 6 is longer than the other lines. Therefore, the expansion of the lines 79,82 and 83 is more economical than the application of BSS, and the application of a BSS on node 5 is more economical than the expansion of the line 6 .

\section{Conclusions}

In the context of this research work, a new planning methodology was developed in the form of a planning algorithm for distribution power systems. The proposed approach aims to determine the cost-optimal and needs-oriented reinforcement measures for distribution grids. For that, traditional planning instruments such as the grid expansion with underground cables as well as innovative planning instruments such as BSS and DPC were applied to ensure the prevention of prognosticated congestions. Besides the total occurring planning costs, the planning algorithm delivers the type and the location of the required expansion measures, as well as the storage capacity, rated power and the location of the required BSS. The results include also the scheduling of the DPC and of the BSS.

The planning algorithm was tested on a real MV grid for different planning variants and compared with the results of the classical planning method. It can be deduced from the result evaluation that the traditional grid planning could in some cases lead to an overdimensioning or an underdimensioning of the grid. Furthermore, the traditional grid expansion measures based on underground cables are not always the most economical solution for the grid planning. In the case of the considered MV grid, the application of DPC has proven to be the most economical solution. The combination of grid expansion and BSS has also proven to be more economical than mere grid expansion. Furthermore, it can be deduced from the results of the planning algorithm that the grid expansion is appropriate for short lines or lines with relatively high overloads, whereas the application of BSS is convenient in case of short overloads on long lines. The planning results in this work cannot be generalized or directly applied on other grids. An individual analysis by means of the planning algorithm remains necessary to determine the most economical and needs-oriented reinforcement measures of each power system.

The presented results in this work are based on simplifications including the simplifications adopted for the linearization of the LFC, and the assumption regarding a perfect prognosis of the load consumption and the feed-in power of RES. In reality, these prognosis are not perfect and are associated with errors. A deviation of the real load consumption or feed-in power from the prognosticated value could lead to a different BSS dimensioning, different DPC results and different grid expansion measures. Therefore, the presented planning results in this work are not to be considered as absolute exact values. Furthermore, the efficient application of BSS and DPC in the grid operation require as well a good approximation of the load and the feed-in behavior to prevent grid congestion efficiently. In order to improve the reliability of these innovative planning instruments in preventing congestion, a safety reserve could be added to the dimensioned capacity and rated power of the BSS, and a margin of safety could be adopted by the application of the DPC.

Besides, further planning instruments such as tap-changer transformers, weatherdependent current rating of overhead lines or the possibility of adding completely new routes for additional power lines could be included in the planning algorithm. 
Author Contributions: Conceptualization, O.L.; methodology, O.L.; software, O.L.; validation, O.L; formal analysis, O.L.; investigation, O.L.; resources, K.R.; data curation, O.L.; writing-original draft preparation, O.L.; writing-review and editing, O.L. and K.R.; visualization, O.L.; supervision, K.R; project administration, O.L. and K.R.; funding acquisition, K.R. All authors have read and agreed to the published version of the manuscript.

Funding: This research has been supported by the Project Management Agency Karlsruhe Institute of Technology (KIT) with funds from the state of Baden-Württemberg.

Conflicts of Interest: The authors declare no conflict of interest.

\section{References}

1. Rehtanz, C.H.; Greve, M.A.; Häger, U.; Hagemann, Z.I.; Kippelt, S.T.; Kittl, C.H.; Kloubert, M.L.; Pohl, O.L.; Rewald, F.L.; Wagner, C.H. Verteilnetzstudie für das Land Baden-Württemberg; Ministerium für Umwelt, Klima und Energiewirtschaft Baden-Württemberg: Dortmund, Germany, 2017.

2. Höflich, B.; Richard, P.; Völker, J.; Rehtanz, C.; Greve, M.; Gwisdorf, B.; Kays, J.; Noll, T.; Schwippe, J.; Seack, A.; et al. DenaVerteilnetzstudie Ausbau-Und Innovationsbedarf der Stromverteilnetze in Deutschland bis 2030; Deutsche Energie-Agentur: Berlin, Germany, 2012.

3. Resch, M.; Bühler, J.; Klausen, M.; Sumper, A. Impact of operation strategies of large scale battery systems on distribution grid planning in Germany. Renew. Sustain. Energy Rev. 2017, 74, 1042-1063. [CrossRef]

4. Liebenau, V.; Schwippe, J.; Kuch, S.; Rehtanz, C. Network extension planning considering the uncertainty of feed-in from renewable energies. In Proceedings of the 2013 IEEE Grenoble Conference, Grenoble, France, 16-20 June 2013; pp. 1-6.

5. Wiest, P. Probabilistische Verteilnetzplanung zur Optimierten Integration Flexbibler Dezentraler Erzeuger und Verbraucher; Sierke: Göttingen, Germany, 2018.

6. Abbey, C.; Baitch, A.; Bak-Jensen, B.; Carter, C.; Celli, G.; El Bakari, K.; Fan, M.; Georgilakis, P.; Hearne, T.; Ochoa, L.N.; et al. Planning and Optimization Methods for Active Distribution Systems; CIGRE Brochure Number 591; CIGRE: Paris, France, 2014.

7. Mexis, I.; Todeschini, G. Battery Energy Storage Systems in the United Kingdom: A Review of Current State-of-the-Art and Future Applications. Energies 2020, 13, 3616. [CrossRef]

8. Tachibana, M.; Palmer, M.D.; Matayoshi, H.; Senjyu, T.; Funabashi, T. Improvement of power system voltage stability using battery energy storage systems. In Proceedings of the 2015 International Conference on Industrial Instrumentation and Control (ICIC), Pune, India, 28-30 May 2015; pp. 317-321.

9. Kawabe, K.; Yokoyama, A. Study on short-term voltage stability improvement using batteries on extra-high voltage network. In Proceedings of the 2013 IEEE Grenoble Conference, Grenoble, France, 16-20 June 2013; pp. 1-3.

10. Sagara, M.; Sediqi, M.M.; Senjyu, T.; Danish, M.S.S.; Funabashi, T. Voltage stability improvement by optimal active power and reactive power output control of storage battery system. In Proceedings of the 2016 IEEE Region 10 Conference (TENCON), Singapore, 22-25 November 2016; pp. 2671-2674.

11. Laribi, O.; Wiest, P.; Rudion, K. Optimal dimensioning and operation of a grid-supporting energy storage system. In Proceedings of the 2017 IEEE PES Innovative Smart Grid Technologies Conference Europe (ISGT-Europe), Turin, Italy, 26-29 September 2017; pp. 1-6. [CrossRef]

12. Buchner, M.; Laribi, O.; Rudion, K. Bestimmung der Betriebsweise eines Speichers zur Netzentlastung auf Basis Linearer Optimierung. In Proceedings of the Tagung Zukünftige Stromnetze für Erneuerbare Energien 2018, Berlin, Germany, 30-31 January 2018; p. S.235.

13. Laribi, O.; Wiest, P.; Rudion, K. Dimensioning and Positioning of Storage Systems under the consideration of the (n-1) Security Criterion in High Voltage distribution Grids. In Proceedings of the 2018 IEEE PES Innovative Smart Grid Technologies Conference Europe (ISGT-Europe), Sarajevo, Bosnia-Herzegovina, 21-25 October 2018.

14. Laribi, O.; Rudion, K.; Lübbe, T. Optimal Planning of High-Voltage Distribution Grids under the Combined Use of Energy Storage Systems and Dynamic Feed-In Management. In Proceedings of the 25th International Conference on Electricity Distribution, Madrid, Spain, 3-6 June 2019.

15. Laribi, O.; Rudion, K.; Schnaars, J. Planung des Hochspannungsnetzes unter Berücksichtigung von Speichern und dynamischer Spitzenkappung. In Proceedings of the Internationaler ETG-Kongress 2019, Esslingen am Neckar, Germany, 8-9 May 2019; p. S.411.

16. Laribi, O.; Rudion, K.; Nagele, H. Combined Grid-supporting and Market-based Operation Strategy for Battery Storage Systems. In Proceedings of the 2020 6th IEEE International Energy Conference (ENERGYCon), Gammarth, Tunisia, 28 September-1 October 2020; pp. 296-301.

17. Koopmann, S.; Scheufen, M.; Schnettler, A. Integration of stationary and transportable storage systems into multi-stage expansion planning of active distribution grids. In Proceedings of the IEEE PES ISGT Europe 2013, Lyngby, Denmark, 6-9 October 2013; pp. 1-5. [CrossRef]

18. Shen, X.; Shahidehpour, M.; Han, Y.; Zhu, S.; Zheng, J. Expansion Planning of Active Distribution Networks With Centralized and Distributed Energy Storage Systems. IEEE Trans. Sustain. Energy 2016, 8, 126-134. [CrossRef] 
19. Brunner, M. Auswirkungen von Power-to-Heat in Elektrischen Verteilnetzen; Institut für Energieübertragung und Hochspannungstechnik der Universität Stuttgart: Klagenfurt, Germany, 2017.

20. Bolognani, S.; Dorfler, F. Fast power system analysis via implicit linearization of the power flow manifold. In Proceedings of the 2015 53rd Annual Allerton Conference on Communication, Control, and Computing (Allerton), Monticello, IL, USA, 29 September-2 October 2015; pp. 402-409.

21. Bolognani, S.; Zampieri, S. On the Existence and Linear Approximation of the Power Flow Solution in Power Distribution Networks. IEEE Trans. Power Syst. 2016, 31, 163-172. [CrossRef]

22. Glover, J.D.; Sarma, M.S.; Overbye, T.J. Power System Analysis and Design, 5th ed.; Cengage Learning: Stamford, CA, USA, 2010.

23. ads-tec Holding GmbH. Available online: https:/ / www.ads-tec-energy.com/ (accessed on 15 August 2021).

24. Newspaper Maeil Business, Hyundai Electric to build 150-MW ESS for Korea Zinc. 2017. Available online: https://pulsenews.co. kr/view.php?year=2017\&no=505105 (accessed on 15 August 2021).

25. Tesla Battery Storage Power Plant. South Australia. 2017. Available online: https://www.spiegel.de/wirtschaft/unternehmen/ tesla-nimmt-in-australien-weltgroesste-batterie-in-betrieb-a-1181326.html (accessed on 24 September 2020).

26. WEMAG Battery Storage Power Plant. Schwerin, Germany. Available online: https://www.wemag.com/sites/default/files/20 170714\%20Faktenblatt\%20WEMAG\%20Batteriespeicher.pdf (accessed on 15 August 2021).

27. Battery Storage Power Plant Flensburg. Flensburg, Germany. 2017. Available online: https://www.shz.de/lokales/flensburgertageblatt/grosse-lithium-ionen-batterie-entsteht-bei-flensburg-id16529056.html (accessed on 15 August 2021).

28. Battery Storage Power Plant Wendelstein. Wendelstein, Germany. 2018. Available online: https://www.zfk.de/energie/strom/ artikel/batteriespeicher-wendelstein-ist-in-betrieb-2018-07-17/ (accessed on 1 July 2020).

29. Eins Energie in Sachsen, Batteriespeicher. Chemnitz Germany. Available online: https://www.eins.de/\%C3\%BCber-eins/ infrastruktur/energiewende/batteriespeicher (accessed on 24 September 2020).

30. Fraunhofer Institute for Systems and Innovation Research ISI. High-Energy Batteries 2030+ and Prospects for Future Battery Technologies_Fraunhofer ISI Presents an Updated Energy Storage Roadmap; Fraunhofer Institute for Systems and Innovation Research ISI: Karlsruhe, Germany, 2017.

31. Zapf, M. Stromspeicher und Power-to-Gas im Deutschen Energiesystem, Rahmenbedingungen, Bedarf und Einsatzmöglichkeiten; Springer: Berlin/Heidelberg, Germany, 2017.

32. Available online: https://www.tesla.com/sites/default/files/pdfs/powerwall/Powerwall\%202_AC_Datasheet_en_northamerica. pdf (accessed on 22 August 2021).

33. Tesla. Overall System Specs Powerpack. Available online: https://www.tesla.com/powerpack?redirect=no (accessed on 24 September 2020).

34. Weaver, J.F. USA's Largest Cluster of Batteries, Including Tesla Megapack, Inching Forward. Available online: https:// commercialsolarguy.com/2020/03/03/tesla-megapack-inching-forward/ (accessed on 15 August 2021).

35. Fischer, C.; Brommer, E.; Gröger, J. Photovoltaik Wechselrichter, Entwicklung der Vergabekriterien für ein Klimaschutzbezogenes Umweltzeichen; Öko-Institut e.V: Freiburg, Germany, 2012.

36. Brakelmann, H. Netzverstärkungs-Trassen zur Übertragung von Windenergie: Freileitung oder Kabel? The German Wind Energy Association (Bundesverband WindEnergie e.V): Rheinberg, Germany, 2004.

37. Bundesnetzagentur. Quarter Report about Grid and System Security Measures for the Year and Fourth Quarter of 2018; Bundesnetzagentur: Bonn, Germany, 2019. 